Requests for reprints and Reserve Tables should be made to Dr. H. A. Dewar, Royal Victoria Infirmary, Newcastle upon Tyne NE1 4LP.

Our thanks are due to Professor D. J. Newell and his staff at the University of Newcastle upon Tyne for preparing the allocation envelopes and for statistical advice; to the pharmacists of the various hospitals for their careful co-operation in dispensing; to the patients themselves who took part; to Imperial Chemical Industries Limited (Pharmaceuticals Division), who supplied all the capsules and financed the project, and in particular to $\mathrm{Mr}$. J. M. Thorp and his staff, who performed all the biochemical analyses; and above all to Dr. C. C. Downie, also of Imperial Chemica Industries Limited, who, with other members of his medical and statistical team, has gone to endless trouble over the analysis of results.

\section{References}

Beaumont, J. L., et al. (1970). Bulletin of the World Health Organization, 43, 891 .

Connerty, H. V., Briggs, A. R., and Eaton, E. H. (1961). Clinical Chemistry,

Fredrickson, D. S., Levy, R. I., and Lees, R. S. (1967). New England fournal of Medicine, 276, 34, 94, 148, 215, 273.

Green, K. G., Inman, W. H. W., and Thorp, J. M. (1963). Fournal of Atherosclerosis Research, 3, 593.

Stone, M. C., Thorp, J. M., Mills, G. L., and Dick, T. B. S. (1970). Clinica Chimica Acta, 30, 809.

Symposium on Atromid. (1963). Fournal of Atherosclerosis Research, 3, 341

\title{
Ischaemic Heart Disease: A Secondary Prevention Trial Using Clofibrate
}

\section{Report by a Research Committee of the Scottish Society of Physicians*}

British Medical fournal, 1971, 4, 775-784

\section{Summary}

A trial is reported of the effects of giving clofibrate to prevent progression of pre-existing ischaemic heart disease. There were two groups randomly distributed between clofibrate (350 patients) and placebo (367 patients) regimens. The trial lasted about six years and was conducted in 19 hospitals in Scotland. The criteria of acceptance into the trial were precise and were monitored by one observer. The standards of diagnosis of events were defined and all protocols and electrocardiograms were read blind by one observer.

Three categories of patients were admissible to the trial: (1) patients with one myocardial infarction (W.H.O. E.C.G. criteria) between 8 and 16 weeks before the start of the trial; (2) patients with angina of a duration of 3 to 24 months, provided their E.C.G. showed signs of myocardial ischaemia at rest or after exercise; and (3) patients with one recent myocardial infarction and pre-existing angina as defined above.

There were fewer deaths in patients with angina (categories 2 and 3 above) treated with clofibrate than in those on placebo. The mortality in the former group was

*Co-ordinator: Dr. M. F. Oliver, Department of Cardiology, Royal Infirmary, Edinburgh.

Participants: Professor S. Alstead, Stobhill General Hospital, Glasgow Dr. J. D. Aitchison, Royal Infirmary, Stirling; Dr. J. Barclay Barr, Royal Infirmary, Kilmarnock; Dr. T. B. Begg, Victoria Infirmary, Glasgow; Dr. P. N. Bennett, Royal Infirmary, Aberdeen; Dr. J. W. Buchanan, Victoria Hospital, Kirkcaldy; Dr. A. J. V. Cameron, Western Infirmary, Glasgow; Dr. W. D. H. Conacher, Bangour Hospital, Broxburn; Dr. Hugh Conway, Royal Alexandra Infirmary, Paisley; Dr. George M. Currie Royal Infirmary, Kilmarnock; Dr. E. B. French, Western General Hospital, Edinburgh; the late Professor H. W. Fullerton, Royal Infirmary, Aberdeen Dr. W. R. Gauld, Woodend General Hospital, Aberdeen; Dr. W. Gray, Bridge of Earn Hospital, Perthshire; Dr. M. Keith, Bruntsfield Hospital, Edinburgh; the late Dr. J. Laurie, Dumfries and Galloway Royal Infirmary, Dumfries; Dr. S. McAlpine, Royal Alexandra Infirmary, Paisley; Professor Dumfries; Dr. S. McAlpine, Royal Alexandra Infirmary, Paisley; Professor A. G. Macgregor, Royal Infirmary, Aberdeen; Dr. G. D. Malcolm, Bridge of Earn Hospital, Perthshire; Dr. W. G. Manderson, Royal Infirmary, Glasgow; Dr. M. B. Matthews, Western General Hospital, Edinburgh Dr. J. S. Meredith, Bridge of Earn Hospital, Perthshire; Dr. K. Morris Hairmyres Hospital, East Kilbride; Dr. M. F. Oliver, Royal Infirmary, Edinburgh; Dr. K. N. V. Palmer, Royal Infirmary, Aberdeen; Dr. A. A. F Peel, Victoria Infirmary, Glasgow; Dr. A. S. Rogen, Stobhill General Hospital, Glasgow; Dr. G. B. Shaw, Southern General Hospital, Glasgow; Dr. A. W. M. Smith, Victoria Hospital, Kirkcaldy; Dr. J. M. Stowers Royal Infirmary, Aberdeen; Professor J. A. Strong, Western General Hospital, Edinburgh; Dr. R. B. Wilson, Dumfries and Galloway Royal Infirmary, Dumfries; Dr. W. M. Wilson, Royal Infirmary, Perth. reduced by $62^{\circ}$, and this is a statistically significant difference. Clofibrate did not have any statistically significant effect in reducing the rate of non-fatal infarction in patients with angina or in those with myocardial infarction and pre-existing angina, though a beneficial trend was evident when both subgroups were combined (a $44 \%$ reduction compared with the placebo group). There was a significant reduction in all events (fatal and non-fatal) in patients with angina ("all anginas") in the clofibrate-treated group; the rate was reduced by $53 \%$.

Clofibrate did not alter the overall mortality or morbidity rates in patients admitted to the trial with recent myocardial infarction without preceding angina of more than three months' duration. In one subgroup there was a statistically significant adverse effect in the clofibrate-treated group. The lack of any overall effect in patients with myocardial infarction might be related to the unexpectedly low mortality rate $(2.97 \%)$ in the placebo group; it is usually in the region of $4-9 \%$ per annum after first myocardial infarction.

In patients categorized as "all anginas" there was significant reduction in events whether the initial serum cholesterol level was high (greater than $260 \mathrm{mg} / 100 \mathrm{ml}$ ) or normal. Clofibrate seemed to have a small but not significant beneficial effect in patients with myocardial infarction with initially high serum cholesterol levels, but was of no value in those with initially normal serum cholesterol levels. There was no significant relationship between the response or lack of response of serum cholesterol to clofibrate and the incidence of events either in patients with angina or in those with infarction.

The main conclusion of this trial is that clofibrate had a beneficial effect in reducing mortality and, to a lesser extent, morbidity in patients who presented with angina ("all anginas"). This effect was independent of initial serum cholesterol levels or the extent to which serum cholesterol was lowered. The drug had no significant overall effect on prognosis in patients with myocardial infarction alone.

\section{Introduction}

Much emphasis has been given to the association between hyperlipidaemia and ischaemic heart disease. The risk of apparently healthy individuals developing ischaemic heart 
disease is increased when hypercholesterolaemia is present (Kagan et al., 1962; Stamler, 1964; Truett et al., 1967). Raised plasma levels of cholesterol and triglycerides occur in many patients with angina pectoris and myocardial infarction, and in those with angina there is an association between hypercholesterolaemia and prognosis (Westlund and Nicolaysen, 1966; Frank et al., 1970) though this may not be so in patients who have had myocardial infarction (Paterson et al., 1963; Little et al., 1965; Frank et al., 1970). The benefit of controlling hyperlipidaemia either in healthy individuals (primary prevention) or in patients with ischaemic heart disease (secondary prevention) can be tested only by establishing large-scale clinical trials.

When the initial short-term trials (Oliver, 1962, 1963; Hellman et al., 1963) of clofibrate had been completed and when it seemed fairly certain that it had no toxic effects and only minimal side effects, the decision was taken to use this drug as a means of testing the value of reducing raised serum lipids in patients with ischaemic heart disease. At the inception of the trial it was recognized that clofibrate influenced various coagulation indices also and that a beneficial result need not necessarily be due to reduction of serum lipids. In view of the lack of firm information concerning the supposition that reduction of serum lipids would be associated with a lower morbidity and mortality rate in such patients, it was decided that the establishment of a formal trial with control groups was ethically justified. This paper is the report of such a trial.

\section{Design of Trial}

The trial was conducted in 19 hospitals in Scotland. The participating physicians agreed to observe a uniform protocol. All data forms were sent to a co-ordinating centre in Edinburgh and subsequently prepared for computer analysis.

The following categories of patients of either sex, aged 40-69 years, were admissible:

(1) Patients presenting with their first myocardial infarct 8 to 16 weeks before admission to the trial. These patients were designated as "myocardial infarct only" and did not have preceding angina of more than three months' duration. Those who had had a previous myocardial infarct were not admissible to the trial.

(2) Patients with angina of not more than two years' and not less than three months' duration, provided E.C.G. signs of ischaemia (W.H.O., 1959) were present in the resting record or after exercise. These patients were designated as "angina only." Those with angina and normal electrocardiograms were not admitted to the trial. Those presenting with angina but with E.C.G. signs of previous myocardial infarction were not admitted to the trial.

(3) Patients presenting with their first myocardial infarct 8 to 16 weeks before admission to the trial who had preceding angina of more than three months' and less than 24 months' duration. These patients were designated as "angina + myocardial infarction." The criterion used for assessing the presence of preceding angina was that the patient had consulted a doctor on this account any time during the stated period.

The purpose of relating admissibility to the trial to a specific time after myocardial infarction and to a specific duration of preceding angina was to obtain relatively homogeneous groups of these respective populations so far as long-term prognosis is concerned.

The only other categories excluded were of patients who had cardiac failure which required treatment with digoxin and/or diuretics and patients with diabetes mellitus.

The criteria for myocardial infarction were: $(a)$ an electrocardiogram codable according to the W.H.O. (1959) criteria for "very probable" myocardial infarction, and (b) an electrocardiogram coded as "possible" myocardial infarction provided there was associated rise in serum enzymes during the acute phase. The presence of a classical clinical history without these criteria did not permit inclusion of patients into the study. All the electrocardiograms were read and coded by one observer (M.F.O.) before the patients were regarded as admissible into the study and before randomization.
Serum enzymes were regarded as abnormal when serum creatine phosphokinase was greater than 100 international units, or serum aspartate aminotransferase (G.O.T.) was greater than $60 \mathrm{IU}$, or serum hydroxybutyric dehydrogenase was greater than 250 IU.

There were two groups of patients in the trial:

(1) Double-blind Group.-This comprised 537 patients not receiving anticoagulants. Neither the patients nor the examining doctors were aware of the "treatment" group to which the patient had been allocated.

(2) Anticoagulant Group.-This comprised 180 patients also given warfarin sodium. Because of potential difficulties in controlling the prothrombin time in patients receiving clofibrate and warfarin sodium the examining doctors knew which patients were allocated to the treatment group: this information was not available to the patients themselves.

Acceptable patients were admitted between August 1964 and October 1968 and the trial ended in April 1970. In both groups patients were allocated at random between two treatment groups: one was given clofibrate 1.6 or $2 \mathrm{~g}$ daily (specially prepared $400-\mathrm{mg}$ capsules) according to weight (less than or more than $140 \mathrm{lb} ; 63.5 \mathrm{~kg}$ ) and the other olive oil dispensed in identical capsules.

\section{Conduct of Trial}

A full clinical examination was undertaken on entry into the study, electrocardiograms and $x$-ray films were taken and a standard protocol was completed.* Serum cholesterol was estimated in a central laboratory by an automated method (Green et al., 1963). The patients were seen at three-monthly intervals throughout the duration of the trial and on each occasion a clinical history was taken, a clinical examination was undertaken, blood was obtained for serum cholesterol determination, and an electrocardiogram was recorded. In the later phases of the trial estimations were made of serum levels of clofibrate, and $96^{\circ}{ }_{0}$ of the patients were found to be adhering to the treatment. The information obtained from these examinations were recorded on a standard form coded for computer analysis.*

The pharmacist in each hospital was supplied with a list of the names of each patient, their allocated numbers, and the code concerning treatment group. The physicians knew only the serial number allocated.

At each visit a pack of capsules containing a three-month supply was made available to those in the double-blind group without the physician being aware of their contents. All general practitioners were informed that their patients were participating in this trial. No restrictions were placed on the use of other treatment. No other preventive measures were specifically introduced and restriction of dietary fat or of cigarette smoking was not included in the regimens. Calorie reduction was encouraged in overweight patients.

\section{END-POINTS}

Sudden death, fatal myocardial infarction, and non-fatal definite and non-fatal probable myocardial infarction were the only events assessed in this study.

Information was obtained by a special questionnaire* at the end of the trial concerning the time relationship of death and the onset of symptoms and concerning the evidence for the diagnosis in all deaths. This was obtained from hospital physicians, general practitioners, and the Registrar General for Scotland. (1) Sudden death was defined as death occurring within one hour of the onset of symptoms or one hour of being witnessed to be alive. (2) Fatal myocardial infarction was defined as death occurring due to a cardiac cause-for example, arrhythmias, shock, or failure between one hour and 28 days after the onset 
of the initial symptoms of acute heart attack. (3) Non-fatal definite myocardial infarction was defined as an E.C.G. change sufficient to meet the W.H.O. (1959) criteria of "very probable" myocardial infarction. This included both the use of a code additional to the original code-that is, when the second myocardial infarction occurred in a different site from the firstand further employment of the same code-that is, when myocardial infarction recurred in the same site as the first. Raised serum enzyme levels and a clinical history were not essential for this definition. (4) Non-fatal probable myocardial infarction was defined as a rise in serum enzyme levels and a clinical history suggestive of myocardial infarction in the absence of a codable E.C.G. change.

No other evidence was accepted. Rise in serum enzymes is defined above.

Whenever the consultant physician in charge of the patients had reason to think that there might have been a further myocardial infarct, either from the clinical history or from E.C.G. changes, the clinical protocols and electrocardiograms were sent to the co-ordinating centre. These were assessed by one observer (M.F.O.), who had no knowledge of the treatment group, and the electrocardiograms were compared with the initial ones. A similar blind assessment was made of the protocols describing the circumstances of death and necropsy records. In addition, at the end of the trial the case records of all patients recorded as having a fresh myocardial infarct were examined without knowledge of the treatment group by one observer (M.F.O.).

\section{STATUS ON ENTRY}

A total of 593 men and 124 women with ischaemic heart disease (as defined) were admitted to the study-288 men were allocated to the clofibrate group and 305 to the placebo group; 62 women were in the treated group and 62 in the placebo group. These patients have been grouped in most tables under five categories: (1) angina only (previously defined); (2) myocardial infarct only (previously defined); (3) angina + myocardial infarctthis category comprises patients with recent myocardial infarction ( 8 to 16 weeks earlier) who also had experienced angina of a duration of not less than three months and not more than two years before the occurrence of infarction; (4) all anginasa combination of 1 and 3 ; and (5) all infarcts-a combination of 2 and 3.

The random allocation of patients between clofibrate and placebo groups was not entirely successful for certain biological indices. The numbers allocated to the groups and the status of these patients on entry into the trial are shown in Table I. Attention is drawn to the significant difference in the mean values for initial serum cholesterol between all men in the clofibrate group $(259 \mathrm{mg} / 100 \mathrm{ml})$ and all men in the placebo group $(272 \mathrm{mg} / 100 \mathrm{ml})$. This difference was present in all subcategories, but the major contribution comes from the "infarct only" group by virtue of providing the greatest difference and the largest number of patients. In the combined group the mean systolic blood pressure and mean serum cholesterol levels were higher in men in the placebo group; this was mostly due to differences in these indices in the doubleblind group.

Table II shows the smoking habits on entry into the trial. There were no significant differences between the groups.

The distribution of height and weight of patients in each group, the age and sex distribution (Reserve Table $1^{\dagger}$ ), the distribution of systolic (Reserve Table 2) and diastolic (Reserve Table 3) blood pressure by treatment group, and the duration of angina (Reserve Table 4) within the groups before entry into the trial were all examined and found to be closely comparable. There was a difference in the distribution of initial serum cholesterol by age and sex and this is shown in Reserve Table 5.

\section{WITHDRAWALS}

The number of withdrawals from the trial are shown in Table III. There was no difference between the clofibrate and placebo $\dagger$ †eserve tables available on request.

\begin{tabular}{|c|c|c|c|c|c|c|c|}
\hline & & $\begin{array}{c}\text { Total } \\
\text { No. }\end{array}$ & $\begin{array}{l}\text { Never } \\
\text { Smoked }\end{array}$ & $\begin{array}{c}\text { Stopped } \\
\text { before Entry } \\
\text { into Trial } \\
\end{array}$ & $\begin{array}{l}\text { Pipe } \\
\text { and/or } \\
\text { Cigars }\end{array}$ & $\begin{array}{l}1-14 \\
\text { Cigs } / \\
\text { Day }\end{array}$ & $\begin{array}{c}15 \text { or } \\
\text { more } \\
\text { Cigs/Day }\end{array}$ \\
\hline \multicolumn{8}{|c|}{ Double-blind } \\
\hline $\begin{array}{l}\text { Clofibrate: } \\
\text { Men }\end{array}$ & $\ldots$ & 207 & 25 & 57 & 9 & 39 & \\
\hline $\begin{array}{l}\text { Women } \\
\text { Placebo: }\end{array}$ & .. & 57 & 20 & 9 & 0 & 21 & 15 \\
\hline $\begin{array}{l}\text { Men } \\
\text { Women }\end{array}$ & $\therefore$ & $\begin{array}{r}219 \\
54\end{array}$ & $\begin{array}{l}21 \\
23\end{array}$ & $\begin{array}{l}76 \\
10\end{array}$ & $\begin{array}{r}15 \\
0\end{array}$ & $\begin{array}{l}37 \\
17\end{array}$ & $\begin{array}{r}78 \\
7\end{array}$ \\
\hline \multicolumn{8}{|c|}{ Anticoagulant } \\
\hline $\begin{array}{l}\text { Clofibrate: } \\
\text { Men }\end{array}$ & & & & & & & \\
\hline $\begin{array}{c}\text { Men } \\
\text { Women } \\
\text { Placebo: }\end{array}$ & $\because$ & $\begin{array}{r}11 \\
5\end{array}$ & 1 & 2 & 0 & 1 & 1 \\
\hline $\begin{array}{l}\text { Placebo: } \\
\text { Men } \\
\text { Women }\end{array}$ & $\because$ & $\begin{array}{r}86 \\
8\end{array}$ & $\begin{array}{l}8 \\
3\end{array}$ & $\begin{array}{r}25 \\
3\end{array}$ & $\begin{array}{l}6 \\
0\end{array}$ & $\begin{array}{r}18 \\
3\end{array}$ & $\begin{array}{r}34 \\
0\end{array}$ \\
\hline \multicolumn{8}{|c|}{ Combined } \\
\hline $\begin{array}{l}\text { Clofibrate: } \\
\text { Men } \\
\text { Women }\end{array}$ & . & $\begin{array}{r}288 \\
62\end{array}$ & $\begin{array}{l}30 \\
21\end{array}$ & $\begin{array}{l}80 \\
11\end{array}$ & $\begin{array}{r}17 \\
0\end{array}$ & $\begin{array}{l}55 \\
22\end{array}$ & $\begin{array}{r}124 \\
16\end{array}$ \\
\hline $\begin{array}{l}\text { Placebo: } \\
\text { Men } \\
\text { Women }\end{array}$ & . & $\begin{array}{r}305 \\
62\end{array}$ & $\begin{array}{l}29 \\
26\end{array}$ & $\begin{array}{r}101 \\
13\end{array}$ & $\begin{array}{r}21 \\
0\end{array}$ & $\begin{array}{l}55 \\
20\end{array}$ & $\begin{array}{r}112 \\
7\end{array}$ \\
\hline
\end{tabular}

Several patients recorded more than one smoking habit, hence the discrepancies in the totals.

TABLE I-Status on Entry

\begin{tabular}{|c|c|c|c|c|c|c|c|c|c|c|c|c|c|}
\hline & & \multirow{2}{*}{$\begin{array}{l}\text { Total } \\
\text { No. }\end{array}$} & \multirow{2}{*}{$\begin{array}{l}\text { Angina } \\
\text { Only }\end{array}$} & \multirow{2}{*}{$\begin{array}{c}\text { Infarct } \\
\text { Only }\end{array}$} & \multirow{2}{*}{$\underset{\text { Infarct }}{\text { Angina }}+$} & \multirow{2}{*}{ Age } & \multirow{2}{*}{$\begin{array}{c}\text { Ht./Wt. } \\
\text { Index }\end{array}$} & \multicolumn{2}{|c|}{ Blood Pressure (mm $\mathrm{Hg}$ ) } & \multirow{2}{*}{$\begin{array}{l}\text { Cholesterol } \\
(\mathrm{mg} / 100 \mathrm{ml})\end{array}$} & \multicolumn{3}{|c|}{ Anticoagulant during Initial Even } \\
\hline & & & & & & & & Systolic & Diastolic & & Never on & Ceased & Continuing \\
\hline \multicolumn{14}{|c|}{ Double-blind } \\
\hline Clofibrate: & & & & & & & & & & & & & \\
\hline Men & & 207 & 49 & 124 & 34 & $51.5 \pm 7.9$ & 3.56 & $137 \pm 21 \ddagger$ & $86 \pm 11 \ddagger$ & $259 \pm 50 \ddagger$ & 114 & 90 & 3 \\
\hline $\begin{array}{l}\text { Women } \\
\text { Placebo: }\end{array}$ & & 57 & 28 & 19 & 10 & $54.8 \pm 7.4$ & 3.59 & $154 \pm 28$ & $92 \pm 12^{+}$ & $287 \pm 49$ & 43 & 13 & 1 \\
\hline $\begin{array}{l}\text { Men } \\
\text { Women }\end{array}$ & $\begin{array}{l}\cdots \\
\cdots\end{array}$ & $\begin{array}{r}219 \\
54\end{array}$ & $\begin{array}{l}64 \\
24\end{array}$ & $\begin{array}{r}119 \\
20\end{array}$ & $\begin{array}{l}36 \\
10\end{array}$ & $\left|\begin{array}{l}52 \cdot 4 \pm 7 \cdot 7 \\
53 \cdot 3 \pm 7 \cdot 2\end{array}\right|$ & $\begin{array}{l}3.58 \\
3.52\end{array}$ & $\begin{array}{l}143 \pm 24 \\
146 \pm 26\end{array}$ & $\begin{array}{l}90 \pm 13 \\
90 \pm 13\end{array}$ & $\begin{array}{l}272 \pm 50 \\
297 \pm 70\end{array}$ & $\begin{array}{r}129 \\
38\end{array}$ & $\begin{array}{l}89 \\
16\end{array}$ & $\begin{array}{l}1 \\
0\end{array}$ \\
\hline \multicolumn{14}{|c|}{ Anticoagulant } \\
\hline Clofibrate: & & & & & & & & & & & & & \\
\hline $\begin{array}{l}\text { Men } \\
\text { Women }\end{array}$ & $\cdots$ & $\begin{array}{r}81 \\
5\end{array}$ & $\begin{array}{r}13 \\
0\end{array}$ & $\begin{array}{r}56 \\
4\end{array}$ & 12 & $51 \cdot 3 \pm 7 \cdot 7$ & 3.67 & $136 \pm 21$ & $88 \pm 14$ & $273 \pm 51$ & & & \\
\hline Placebo: & & & & & & & & & & $291 \pm 40$ & & & \\
\hline $\begin{array}{l}\text { Men } \\
\text { Women }\end{array}$ & 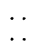 & $\begin{array}{r}86 \\
8\end{array}$ & $\begin{array}{r}15 \\
1\end{array}$ & $\begin{array}{r}56 \\
5\end{array}$ & $\begin{array}{r}15 \\
2\end{array}$ & $\left|\begin{array}{l}50.9 \\
52.5 \\
\pm 7.9\end{array}\right|$ & $\begin{array}{l}3.60 \\
3.95\end{array}$ & $\begin{array}{l}133 \pm 21 \\
148 \pm 24\end{array}$ & $\begin{array}{ll}87 & \pm 12 \\
91 & \pm 16\end{array}$ & $\begin{array}{l}276 \pm 49 \\
305 \pm 70\end{array}$ & & & \\
\hline \multicolumn{14}{|c|}{ Combined } \\
\hline Clofibrate: & & & & & & & & & & & & & \\
\hline Men & .. & 288 & 62 & 180 & 46 & $51.4 \pm 7.8$ & 3.59 & $136 \pm 21^{*}$ & $87 \pm 12$ & $264 \pm 51^{*}$ & & & \\
\hline $\begin{array}{l}\text { Women } \\
\text { Placebo: }\end{array}$ & $\cdots$ & 62 & 28 & 23 & 11 & $54 \cdot 8 \pm 7 \cdot 6$ & 3.61 & $155 \pm 27$ & $92 \pm 11$ & $280 \pm 47$ & & & \\
\hline $\begin{array}{l}\text { Men } \\
\text { Women }\end{array}$ & . & $\begin{array}{r}305 \\
62\end{array}$ & $\begin{array}{l}79 \\
25\end{array}$ & $\begin{array}{r}175 \\
25\end{array}$ & $\begin{array}{l}51 \\
12\end{array}$ & $\begin{array}{l}52.0 \pm 7.5 \\
53.2 \pm 7.1\end{array}$ & $\begin{array}{l}3.59 \\
3.58\end{array}$ & $\begin{array}{l}140 \pm 23 \\
146 \pm 25\end{array}$ & $\begin{array}{l}89 \pm 13 \\
90 \pm 13\end{array}$ & $\begin{array}{l}273 \pm 50 \\
300 \pm 67\end{array}$ & & & \\
\hline
\end{tabular}

A significant difference in the clofibrate group from the corresponding measurement in the placebo group is indicated by $* P<0 \cdot 05, \dagger P<0 \cdot 02, \ddagger P<0 \cdot 01$. 
groups or in any subgroup. In Tables IV and $\mathrm{V}$ the status on entry of the patients who withdrew from the trial is outlined. In the double-blind group more younger men withdrew from the clofibrate than from the placebo group.

\section{DURATION OF TRIAL}

In Table VI the duration of trial in patient-months is indicated. While the trial was essentially six years in duration, there was

TABLE III-Patients Withdrawn

\begin{tabular}{|c|c|c|c|c|c|c|}
\hline \multirow{2}{*}{ Reasons } & \multicolumn{3}{|c|}{ Clofibrate } & \multicolumn{3}{|c|}{ Placebo } \\
\hline & Men & Women & Total & Men & Women & Total \\
\hline \multicolumn{7}{|c|}{ Double-blind } \\
\hline \multirow{4}{*}{ 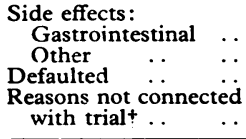 } & & & & & & \\
\hline & 2 & 2 & 4 & 1 & 0 & 1 \\
\hline & $\begin{array}{r}2 \\
16\end{array}$ & $\begin{array}{l}1 \\
7\end{array}$ & 23 & $\begin{array}{r}2 \\
19\end{array}$ & $\begin{array}{l}2 \\
8\end{array}$ & $\begin{array}{r}4 \\
27\end{array}$ \\
\hline & & 2 & 11 & 5 & 4 & 9 \\
\hline Total patients & 29 & 12 & 41 & $25^{*}$ & 14 & $39 *$ \\
\hline $\begin{array}{ccc}\text { Total duration } & \text { in } \\
\text { months } & . . & \ldots \\
\text { Mean } & . . & \ldots\end{array}$ & $\begin{array}{c}498 \\
17 \cdot 8\end{array}$ & $\begin{array}{c}178 \\
13.7\end{array}$ & $\begin{array}{l}676 \\
16.5\end{array}$ & $\begin{array}{c}448 \\
17 \cdot 9\end{array}$ & $\begin{array}{c}256 \\
18 \cdot 3\end{array}$ & $\begin{array}{c}704 \\
18 \cdot 1\end{array}$ \\
\hline
\end{tabular}

\begin{tabular}{|c|c|c|c|c|c|c|}
\hline & & Intico & lant & & & \\
\hline 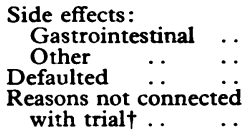 & $\begin{array}{r}2 \\
1 \\
12 \\
3\end{array}$ & $\begin{array}{l}0 \\
0 \\
0 \\
0\end{array}$ & $\begin{array}{r}2 \\
1 \\
12 \\
3\end{array}$ & $\begin{array}{r}1 \\
0 \\
12 \\
4\end{array}$ & $\begin{array}{l}0 \\
0 \\
2 \\
0\end{array}$ & $\begin{array}{r}1 \\
0 \\
14 \\
4\end{array}$ \\
\hline Total patients & $17^{*}$ & 0 & $17^{*}$ & 17 & 2 & 19 \\
\hline $\begin{array}{ccc}\text { Total duration } & \text { in } \\
\text { months } & \ldots & \ldots \\
\text { Mean } \ldots & \ldots & \ldots\end{array}$ & $\begin{array}{c}289 \\
17 \cdot 0\end{array}$ & 二 & $\begin{array}{c}289 \\
17 \cdot 0\end{array}$ & $\begin{array}{c}343 \\
20 \cdot 2\end{array}$ & $\begin{array}{l}53 \\
26.5\end{array}$ & $\begin{array}{l}396 \\
20 \cdot 8\end{array}$ \\
\hline
\end{tabular}

\begin{tabular}{|c|c|c|c|c|c|c|}
\hline & & Comb & & & & \\
\hline 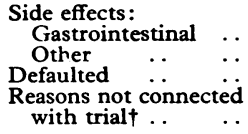 & $\begin{array}{r}4 \\
3 \\
28 \\
12\end{array}$ & $\begin{array}{l}2 \\
1 \\
7 \\
2\end{array}$ & $\begin{array}{r}6 \\
4 \\
35 \\
14\end{array}$ & $\begin{array}{r}2 \\
2 \\
31 \\
9\end{array}$ & $\begin{array}{r}0 \\
2 \\
10 \\
4\end{array}$ & $\begin{array}{r}2 \\
4 \\
41 \\
13\end{array}$ \\
\hline Total patients & $46^{*}$ & 12 & $58^{*}$ & $42 *$ & 16 & $58^{*}$ \\
\hline $\begin{array}{ccc}\text { Total duration } & \text { in } \\
\text { months } & \ldots & \ldots \\
\text { Mean } \ldots & \ldots & \ldots\end{array}$ & $\begin{array}{c}787 \\
17.5\end{array}$ & $\begin{array}{c}178 \\
13 \cdot 7\end{array}$ & $\begin{array}{c}965 \\
16 \cdot 6\end{array}$ & $\begin{array}{c}791 \\
18 \cdot 8\end{array}$ & $\begin{array}{c}309 \\
19 \cdot 3\end{array}$ & $\begin{array}{r}1,100 \\
19 \cdot 0\end{array}$ \\
\hline
\end{tabular}

*Two patients in the double-blind section and one in the anticoagulant section each had two reasons for leaving the trial.
$\dagger$ his includes intercurrent illness and leaving the district.
TABLE V-Patients Withdrawing from Trial: Smoking Habits on Entry

\begin{tabular}{|c|c|c|c|c|c|c|c|}
\hline & & $\begin{array}{l}\text { Total } \\
\text { No. }\end{array}$ & $\begin{array}{l}\text { Never } \\
\text { Smoked }\end{array}$ & $\begin{array}{l}\text { Stopped } \\
\text { before Entry } \\
\text { into Trial }\end{array}$ & $\begin{array}{l}\text { Pipe } \\
\text { and or } \\
\text { Cigars }\end{array}$ & $\begin{array}{c}1-14 \\
\text { Cigs./ } \\
\text { Day }\end{array}$ & $\begin{array}{c}15 \text { or } \\
\text { more } \\
\text { Cigs./Day }\end{array}$ \\
\hline \multicolumn{8}{|c|}{ Double-blind } \\
\hline Clofibrate: & & & & & & & \\
\hline Men & . & 29 & 4 & 5 & 2 & 6 & 17 \\
\hline $\begin{array}{l}\text { Placebo: } \\
\text { Pal }\end{array}$ & & & & & & & \\
\hline Men & . & 25 & 2 & 7 & 4 & 8 & 12 \\
\hline Women & . & 14 & 8 & 4 & 0 & 3 & 2 \\
\hline \multicolumn{8}{|c|}{ Anticoagulant } \\
\hline $\begin{array}{l}\text { Clofibrate: } \\
\text { Men }\end{array}$ & $\ldots$ & 17 & 0 & 7 & 0 & 4 & 11 \\
\hline Women & $\therefore$ & 0 & 0 & 0 & 0 & 0 & 0 \\
\hline $\begin{array}{l}\text { Placebo: } \\
\text { Men }\end{array}$ & 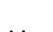 & 17 & 1 & 5 & 2 & 4 & 8 \\
\hline Women & $\therefore$ & 2 & 1 & 1 & 0 & 1 & 1 \\
\hline \multicolumn{8}{|c|}{ Combined } \\
\hline & & & & & & & \\
\hline Men & $\therefore$ & 46 & 4 & 12 & 2 & 10 & 28 \\
\hline $\begin{array}{l}\text { Women } \\
\text { Pocebo: }\end{array}$ & . & 12 & 4 & 1 & 0 & 3 & 4 \\
\hline Men & .. & 42 & 3 & 12 & 6 & 12 & 20 \\
\hline Women & $\cdots$ & 16 & 9 & 5 & 0 & 4 & 3 \\
\hline
\end{tabular}

Several patients recorded more than one smoking habit, hence the discrepancies in the totals.

some variation in the duration in the various groups, and the figures given in Table VI act as an accurate reference only for the determination of death rates. The rates for non-fatal infarcts were calculated from a modified table which includes only the patient-months accumulated to the time of the event, though the patients remained in the trial.

\section{Results}

Three categories of events, defined previously, have been recorded: (1) sudden deaths, (2) fatal myocardial infarction, and (3) first non-fatal myocardial infarct after admission to the trial. (In the case of patients in the angina subgroup, this was their first infarct; in the case of the patients in the infarct subgroup, this was their second infarct, the first infarct having occurred before entry into the trial.) When a patient died after surviving the first non-fatal myocardial infarct both events were recorded (Table VII). Recurrent non-fatal myocardial infarcts have not been included in the results, but figures are available (Reserve Table 6). Deaths due to non-cardiac causes have not been included in the assessment of results.

TABLE IV-Withdrawals: Status on Entry

\begin{tabular}{|c|c|c|c|c|c|c|c|c|c|c|c|}
\hline & & & \multirow{2}{*}{ Total No. } & \multirow{2}{*}{$\begin{array}{c}\text { Angina } \\
\text { Only }\end{array}$} & \multirow{2}{*}{$\begin{array}{l}\text { Infarct } \\
\text { Only }\end{array}$} & \multirow{2}{*}{$\underset{\text { Infarct }}{\text { Angina }}+$} & \multirow{2}{*}{ Age } & \multirow{2}{*}{$\underset{\text { Index }}{\text { Ht./wt. }}$} & \multicolumn{2}{|c|}{ Blood Pressure (mm Hg) } & \multirow{2}{*}{$\begin{array}{l}\text { Cholesterol } \\
(\mathrm{mg} / 100 \mathrm{ml})\end{array}$} \\
\hline & & & & & & & & & Systolic & Diastolic & \\
\hline \multicolumn{12}{|c|}{ Double-blind } \\
\hline $\begin{array}{l}\text { Clofibrate } \\
\text { Men } \\
\text { Women }\end{array}$ & 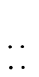 & $\begin{array}{l}\cdots \\
\cdots\end{array}$ & $\begin{array}{l}29 \\
12\end{array}$ & $\begin{array}{l}9 \\
4\end{array}$ & $\begin{array}{r}20 \\
6\end{array}$ & $\begin{array}{l}0 \\
2\end{array}$ & $\begin{array}{l}50 \cdot 5 \pm 8 \cdot 7^{*} \\
56.7 \pm 5 \cdot 8\end{array}$ & $\begin{array}{l}3.49 \\
3.80\end{array}$ & $\begin{array}{l}138 \pm 22 \\
163 \pm 26\end{array}$ & $\begin{array}{l}88 \pm 11 \\
96 \pm 10\end{array}$ & $\begin{array}{c}248 \pm 43 \\
293 \pm 51\end{array}$ \\
\hline $\begin{array}{l}\text { Placebo: } \\
\text { Men } \\
\text { Women }\end{array}$ & $\begin{array}{l}\cdots \\
\cdots\end{array}$ & $\begin{array}{l}\cdots \\
\cdots\end{array}$ & $\begin{array}{l}25 \\
14\end{array}$ & $\begin{array}{l}7 \\
9\end{array}$ & $\begin{array}{r}16 \\
4\end{array}$ & 2 & $\begin{array}{l}55 \cdot 4 \pm 7 \cdot 4 \\
54 \cdot 3 \pm 7 \cdot 3\end{array}$ & $\begin{array}{l}3.55 \\
3.87\end{array}$ & $\begin{array}{l}137 \pm 23 \\
163 \pm 28\end{array}$ & $\begin{array}{l}88 \pm 12 \\
97 \pm 11\end{array}$ & $\begin{array}{l}254 \pm 54 \\
308 \pm 88\end{array}$ \\
\hline \multicolumn{12}{|c|}{ Anticoagulant } \\
\hline $\begin{array}{l}\text { Clofibrate: } \\
\text { Men } \\
\text { Women }\end{array}$ & $\because$ & 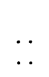 & $\begin{array}{r}17 \\
0\end{array}$ & $\begin{array}{l}1 \\
0\end{array}$ & $\begin{array}{r}12 \\
0\end{array}$ & $\begin{array}{l}4 \\
0\end{array}$ & $52 \cdot 7 \pm 9 \cdot 7$ & 3.51 & $133 \pm 21$ & $87 \pm 14$ & $241 \pm 43 \dagger$ \\
\hline $\begin{array}{l}\text { Placebo: } \\
\text { Men } \\
\text { V. omen }\end{array}$ & $\begin{array}{l}\cdots \\
\cdots\end{array}$ & . & $\begin{array}{r}17 \\
2\end{array}$ & $\begin{array}{l}4 \\
0\end{array}$ & $\begin{array}{r}10 \\
2\end{array}$ & $\begin{array}{l}3 \\
0\end{array}$ & $\begin{array}{l}50 \cdot 3 \pm 7 \cdot 2 \\
60 \cdot 0 \pm 7 \cdot 1\end{array}$ & $\begin{array}{l}3 \cdot 57 \\
3 \cdot 86\end{array}$ & $\begin{array}{l}133 \pm 19 \\
130 \pm 7\end{array}$ & $\begin{array}{l}86 \pm 12 \\
75 \pm 0\end{array}$ & $\begin{array}{l}276 \pm 40 \\
355 \pm 99\end{array}$ \\
\hline \multicolumn{12}{|c|}{ Combined } \\
\hline $\begin{array}{l}\text { Clofibrate: } \\
\text { Men } \\
\text { Women } \\
\text { Wome. }\end{array}$ & $\begin{array}{l}\cdots \\
\cdots\end{array}$ & $\begin{array}{l}\cdots \\
\cdots\end{array}$ & $\begin{array}{l}46 \\
12\end{array}$ & $\begin{array}{r}10 \\
4\end{array}$ & $\begin{array}{r}32 \\
6\end{array}$ & $\begin{array}{l}4 \\
2\end{array}$ & $\begin{array}{l}51 \cdot 3 \pm 9 \cdot 0 \\
56 \cdot 7 \pm 5 \cdot 8\end{array}$ & $\begin{array}{l}3.51 \\
3.80\end{array}$ & $\begin{array}{l}136 \pm 31 \\
163 \pm 26\end{array}$ & $\begin{array}{l}88 \pm 12 \\
96 \pm 10\end{array}$ & $\begin{array}{l}246 \pm 43 \\
293 \pm 51\end{array}$ \\
\hline $\begin{array}{l}\text { Placebo: } \\
\text { Men } \\
\text { Women }\end{array}$ & $\begin{array}{l}. \\
\cdots\end{array}$ & .. & $\begin{array}{l}42 \\
16\end{array}$ & 11 & $\begin{array}{r}26 \\
6\end{array}$ & $\begin{array}{l}5 \\
1\end{array}$ & $\begin{array}{l}53.3 \pm 7.6 \\
55.0 \pm 7.3\end{array}$ & $\begin{array}{l}3.56 \\
3.85\end{array}$ & $\begin{array}{l}135 \pm 22 \\
159 \pm 28\end{array}$ & $\begin{array}{l}87 \pm 12 \\
94 \pm 13\end{array}$ & $\begin{array}{l}256 \pm 61 \\
314 \pm 87\end{array}$ \\
\hline
\end{tabular}

A significant difference in the clofibrate group from the corresponding measurement in the placebo group is indicated by: $* \dot{\mathrm{P}}<0 \cdot 05,+\mathrm{P}<0 \cdot 0$ ?, $\pm \mathrm{P}<0 \cdot 01$. 
TABLE VI-Duration of Trial in Months

\begin{tabular}{|c|c|c|c|c|c|c|c|}
\hline & & \multicolumn{3}{|c|}{ Clofibrate } & \multicolumn{3}{|c|}{ Placebo } \\
\hline & & Men & Women & Total & Men & Women & Total \\
\hline \multicolumn{8}{|c|}{ Double-blind } \\
\hline $\begin{array}{l}\text { Angina } \\
\text { Infarct } \\
\text { Angina }+ \text { infarct } \\
\text { All anginas } \ldots \\
\text { All infarcts } \ldots \\
\end{array}$ & $\begin{array}{l}\cdots \\
\cdots \\
\cdots \\
\cdots\end{array}$ & $\begin{array}{l}1,905 \\
4,720 \\
1,547 \\
3,452 \\
6,267 \\
\end{array}$ & $\begin{array}{r}1,348 \\
645 \\
393 \\
1,741 \\
1,038 \\
\end{array}$ & $\begin{array}{l}3,253 \\
5,365 \\
1,940 \\
5,193 \\
7,305 \\
\end{array}$ & $\begin{array}{l}2,787 \\
5,007 \\
1,412 \\
4,199 \\
6,419 \\
\end{array}$ & $\begin{array}{r}1,057 \\
895 \\
459 \\
1,516 \\
1,354 \\
\end{array}$ & $\begin{array}{l}3,844 \\
5,902 \\
1,871 \\
5,715 \\
7,773 \\
\end{array}$ \\
\hline Total & $\ldots$ & 8,172 & 2,386 & 10,558 & 9,206 & 2,411 & 11,617 \\
\hline
\end{tabular}

Anticoagulant

Patients Still on Anticoagulant

\begin{tabular}{rll|r|r|r|r|r|r} 
Angina & $\ldots$ & $\ldots$ & 334 & 0 & 334 & 330 & 15 & 345 \\
Infarct & $\ldots$ & $\cdots$ & 1,029 & 93 & 1,122 & 1,394 & 58 & 1,452 \\
Angina + infarct & $\ldots$ & 269 & 33 & 302 & 366 & 93 & 459 \\
All anginas & $\ldots$ & $\cdots$ & 603 & 33 & 636 & 696 & 108 & 804 \\
All infarcts & $\cdots$ &. & 1,298 & 125 & 1,424 & 1,760 & 151 & 1,911 \\
\hline Total &.. & 1,632 & 126 & 1,758 & 2,090 & 166 & 2,256 \\
\hline
\end{tabular}

Patients Who Stopped Anticoagulant but Continued Clofibrate or Placebo

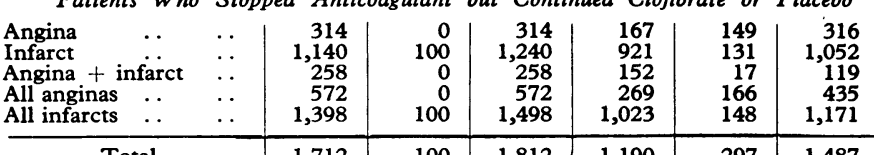

\begin{tabular}{|c|c|c|c|c|c|c|c|}
\hline Total & $\ldots$ & 1,712 & 100 & 1,812 & 1,190 & 297 & 1,487 \\
\hline \multicolumn{8}{|c|}{ Combined } \\
\hline $\begin{array}{l}\text { Angina } \\
\text { Infarct } \\
\text { Angina }+ \text { infarct } \\
\text { All anginas } \quad . \\
\text { All infarcts } \quad .\end{array}$ & $\begin{array}{l}\cdots \\
\cdots \\
\cdots \\
\cdots\end{array}$ & $\begin{array}{l}2,553 \\
6,889 \\
2,074 \\
4,627 \\
8,963\end{array}$ & $\begin{array}{r}1,348 \\
838 \\
426 \\
1,774 \\
1,264\end{array}$ & $\begin{array}{r}3,901 \\
7,727 \\
2,500 \\
6,401 \\
10,227\end{array}$ & $\begin{array}{l}3,284 \\
7,322 \\
1,880 \\
5,164 \\
9,202\end{array}$ & $\begin{array}{r}1,221 \\
1,084 \\
569 \\
1,790 \\
1,653\end{array}$ & $\begin{array}{r}4,505 \\
8,406 \\
2,449 \\
6,954 \\
10,855\end{array}$ \\
\hline Total & $\ldots$ & 11,516 & 2,612 & 14,128 & 12,486 & 2,874 & 15,360 \\
\hline
\end{tabular}

OVERALL RESULTS

In Table VII the number of deaths, the type of death, the percentage mortality, and the death rate per 1,200 patientmonths are shown. The same information is included in this table for non-fatal first myocardial infarcts. These results are shown separately for the double-blind group, anticoagulant group, and combined groups.

While none of the differences shown in Table VII reached statistical significance, there is a trend in favour of the clofibrate group so far as non-fatal first infarcts are concerned. It is also relevant to point out that the annual death rate $(2.97 \%)$ and infarct rate $(3.45 \%)$ in the placebo group were lower than have usually been reported for patients surviving one month after their first myocardial infarct. The range of death rates for patients who have had one myocardial infarct usually varies between 4 and $9 \%$ per annum and the non-fatal first recurrent myocardial infarct rate is usually in the region of $4-11 \%$ (see Discussion).

\section{DEATHS}

In Table VIII the number of deaths and in Table IX the death rate per 1,200 patient-months are shown for the doubleblind, anticoagulant, and combined groups according to the diagnosis on entry into the trial. For those categorized on entry as having "angina + myocardial infarct" there was significant reduction in the double-blind and combined groups in the rate per 1,200 patient-months for those treated with clofibrate compared with those on placebo (combined: clofibrate $1 \cdot 44$, placebo $6 \cdot 86$ ). There was a similar trend in those with

Anticoagulant

\begin{tabular}{|c|c|c|c|c|c|c|c|c|c|c|c|c|c|c|c|c|c|c|c|c|c|c|}
\hline & & & \multicolumn{10}{|c|}{ Clofibrate } & \multicolumn{10}{|c|}{ Placebo } \\
\hline & & & \multicolumn{2}{|c|}{$\begin{array}{l}\text { No. in } \\
\text { Group on } \\
\text { Entry }\end{array}$} & \multicolumn{2}{|c|}{ Sudden } & \multicolumn{2}{|c|}{$\begin{array}{c}\text { Fatal } \\
\text { Infarct }\end{array}$} & \multicolumn{2}{|c|}{$\begin{array}{c}\text { Congestive } \\
\text { H.F. }\end{array}$} & \multicolumn{2}{|c|}{ Total } & \multicolumn{2}{|c|}{$\begin{array}{l}\text { No. in } \\
\text { Group on } \\
\text { Entry }\end{array}$} & \multicolumn{2}{|c|}{ Sudden } & \multicolumn{2}{|c|}{$\underset{\text { Infarct }}{\text { Fatal }}$} & \multicolumn{2}{|c|}{$\begin{array}{c}\text { Congestive } \\
\text { H.F. }\end{array}$} & \multicolumn{2}{|c|}{ Total } \\
\hline & & & M. & F. & A & B & A & B & A & B & A & B & M. & F. & A & B & $\mathbf{A}$ & B & $\mathbf{A}$ & B & $\mathbf{A}$ & B \\
\hline $\begin{array}{l}\text { Angina only } \\
\text { Infarct only } \\
\text { Angina }+ \text { infarct } \\
\text { All anginas } \\
\text { All infarcts }\end{array}$ & $\begin{array}{l}\cdots \\
\cdots \\
\cdots \\
\cdots\end{array}$ & $\begin{array}{l}\cdots \\
\cdots \\
\cdots \\
\cdots\end{array}$ & $\begin{array}{l}13 \\
56 \\
12 \\
25 \\
68\end{array}$ & $\begin{array}{l}0 \\
4 \\
1 \\
1 \\
5\end{array}$ & $\begin{array}{l}0 \\
1 \\
0 \\
0 \\
1\end{array}$ & $\begin{array}{l}0 \\
1 \\
0 \\
0 \\
1\end{array}$ & $\begin{array}{l}0 \\
2 \\
0 \\
0 \\
2\end{array}$ & $\begin{array}{l}0 \\
0 \\
0 \\
0 \\
0\end{array}$ & $\begin{array}{l}0 \\
0 \\
0 \\
0 \\
0\end{array}$ & $\begin{array}{l}0 \\
0 \\
0 \\
0 \\
0\end{array}$ & $\begin{array}{l}0 \\
3 \\
0 \\
0 \\
3\end{array}$ & $\begin{array}{l}0 \\
1 \\
0 \\
0 \\
1\end{array}$ & $\begin{array}{l}15 \\
56 \\
15 \\
30 \\
71\end{array}$ & $\begin{array}{l}1 \\
5 \\
2 \\
3 \\
7\end{array}$ & $\begin{array}{l}0 \\
1 \\
1 \\
1 \\
2\end{array}$ & $\begin{array}{l}0 \\
1 \\
0 \\
0 \\
1\end{array}$ & $\begin{array}{l}0 \\
0 \\
1 \\
1 \\
1\end{array}$ & $\begin{array}{l}0 \\
2 \\
0 \\
0 \\
2\end{array}$ & $\begin{array}{l}0 \\
0 \\
0 \\
0 \\
0\end{array}$ & $\begin{array}{l}0 \\
0 \\
0 \\
0 \\
0\end{array}$ & $\begin{array}{l}0 \\
1 \\
2 \\
2 \\
3\end{array}$ & $\begin{array}{l}\mathbf{0} \\
3 \\
0 \\
0 \\
3\end{array}$ \\
\hline Total . & . & . & 81 & 5 & 1 & 1 & 2 & 0 & 0 & 0 & 3 & 1 & 86 & 8 & 2 & 1 & 1 & 2 & 0 & 0 & 3 & 3 \\
\hline \multicolumn{23}{|c|}{ Double-blind } \\
\hline & & & \multicolumn{10}{|c|}{ Clofibrate } & \multicolumn{10}{|c|}{ Placebo } \\
\hline & & & \multicolumn{2}{|c|}{$\begin{array}{l}\text { No. in } \\
\text { Group on } \\
\text { Entry }\end{array}$} & \multicolumn{2}{|c|}{ Sudden } & \multicolumn{2}{|c|}{$\underset{\text { Infarct }}{\text { Fatal }}$} & \multicolumn{2}{|c|}{$\begin{array}{c}\text { Congestive } \\
\text { H.F. }\end{array}$} & \multicolumn{2}{|c|}{ Total } & \multicolumn{2}{|c|}{$\begin{array}{l}\text { No. in } \\
\text { Group on } \\
\text { Entry }\end{array}$} & \multicolumn{2}{|c|}{ Sudden } & \multicolumn{2}{|c|}{$\underset{\text { Infarct }}{\text { Fatal }}$} & \multicolumn{2}{|c|}{$\begin{array}{c}\text { Congestive } \\
\text { H.F. }\end{array}$} & \multirow{2}{*}{\multicolumn{2}{|c|}{ Total }} \\
\hline & & & M. & F. & M. & F. & M. & F. & M. & F. & & & M. & F. & M. & F. & M. & F. & M. & F. & & \\
\hline $\begin{array}{l}\text { Angina only } \\
\text { Infarct only } \\
\text { Angina }+ \text { infarct } \\
\text { All anginas } \\
\text { All infarcts }\end{array}$ & $\begin{array}{l}\cdots \\
\cdots \\
\cdots\end{array}$ & $\begin{array}{l}\cdots \\
\cdots \\
\cdots \\
\cdots\end{array}$ & $\begin{array}{r}49 \\
124 \\
34 \\
83 \\
158 \\
\end{array}$ & $\begin{array}{l}28 \\
19 \\
10 \\
38 \\
29\end{array}$ & $\begin{array}{r}2 \\
10 \\
1 \\
3 \\
11\end{array}$ & $\begin{array}{l}0 \\
0 \\
0 \\
0 \\
0\end{array}$ & $\begin{array}{r}2 \\
12 \\
2 \\
4 \\
14\end{array}$ & $\begin{array}{l}1 \\
0 \\
0 \\
1 \\
0\end{array}$ & $\begin{array}{l}0 \\
0 \\
0 \\
0 \\
0\end{array}$ & $\begin{array}{l}0 \\
0 \\
0 \\
0 \\
0\end{array}$ & & $\begin{array}{l}5 \\
2 \\
3 \\
8 \\
5\end{array}$ & $\begin{array}{r}64 \\
119 \\
36 \\
100 \\
155\end{array}$ & $\begin{array}{l}24 \\
20 \\
10 \\
34 \\
30\end{array}$ & $\begin{array}{r}5 \\
5 \\
5 \\
10 \\
10\end{array}$ & $\begin{array}{l}1 \\
0 \\
2 \\
3 \\
2\end{array}$ & $\begin{array}{l}3 \\
2 \\
4 \\
7 \\
6\end{array}$ & $\begin{array}{l}0 \\
1 \\
1 \\
1 \\
2\end{array}$ & $\begin{array}{l}\mathbf{0} \\
2 \\
0 \\
0 \\
2\end{array}$ & $\begin{array}{l}0 \\
1 \\
0 \\
0 \\
1\end{array}$ & & $\begin{array}{l}9 \\
1 \\
2 \\
1 \\
3 \\
3\end{array}$ \\
\hline Total & . & . & 207 & 57 & 13 & 0 & 16 & 1 & 0 & 0 & & 0 & 219 & 54 & 15 & 3 & 9 & 2 & 2 & 1 & & 2 \\
\hline \multicolumn{23}{|c|}{ Combined } \\
\hline & & & \multicolumn{10}{|c|}{ Clofibrate } & \multicolumn{10}{|c|}{ Placebo } \\
\hline & & & \multicolumn{2}{|c|}{$\begin{array}{l}\text { No. in } \\
\text { Group on } \\
\text { Entry }\end{array}$} & $\mathrm{Su}$ & & & & $\underset{\mathrm{H}}{\mathrm{Con}}$ & stive & & tal & $\begin{array}{r}\text { Nro } \\
\text { E }\end{array}$ & & & & $\begin{array}{r}\mathrm{Fa} \\
\text { Inf }\end{array}$ & & Con & & & tal \\
\hline & & & M. & $\mathrm{F}$. & M. & F. & M. & F. & M. & F. & & & M. & F. & M. & F. & M. & F. & M. & F. & & \\
\hline $\begin{array}{l}\text { Angina only } \\
\text { Infarct only } \\
\text { Angina }+ \text { infarct } \\
\text { All anginas } \\
\text { All infarcts }\end{array}$ & $\begin{array}{l}\cdots \\
\cdots \\
\cdots\end{array}$ & $\begin{array}{l}\ldots \\
\cdots \\
\cdots \\
\cdots\end{array}$ & $\begin{array}{r}62 \\
180 \\
46 \\
108 \\
226 \\
\end{array}$ & $\begin{array}{l}28 \\
23 \\
11 \\
39 \\
34\end{array}$ & $\begin{array}{r}2 \\
12 \\
1 \\
3 \\
13\end{array}$ & $\begin{array}{l}0 \\
c \\
1 \\
0 \\
0\end{array}$ & $\begin{array}{r}2 \\
14 \\
2 \\
4 \\
16\end{array}$ & $\begin{array}{l}1 \\
0 \\
0 \\
1 \\
0\end{array}$ & $\begin{array}{l}0 \\
0 \\
0 \\
0 \\
0\end{array}$ & $\begin{array}{l}0 \\
0 \\
0 \\
0 \\
0\end{array}$ & & $\begin{array}{l}5 \\
6 \\
3 \\
8 \\
9\end{array}$ & $\begin{array}{r}79 \\
175 \\
51 \\
130 \\
226\end{array}$ & $\begin{array}{l}25 \\
25 \\
12 \\
37 \\
37\end{array}$ & $\begin{array}{r}5 \\
7 \\
6 \\
11 \\
13\end{array}$ & $\begin{array}{l}1 \\
0 \\
2 \\
3 \\
2\end{array}$ & $\begin{array}{l}3 \\
4 \\
5 \\
8 \\
9\end{array}$ & $\begin{array}{l}0 \\
1 \\
1 \\
1 \\
2\end{array}$ & $\begin{array}{l}0 \\
2 \\
0 \\
0 \\
2\end{array}$ & $\begin{array}{l}0 \\
1 \\
0 \\
0 \\
1\end{array}$ & & $\begin{array}{l}9 \\
5 \\
4 \\
3 \\
9\end{array}$ \\
\hline Total & . & . & 288 & 62 & 15 & 0 & 18 & 1 & 0 & 0 & & 4 & 305 & 62 & 18 & 3 & 12 & 2 & 2 & 1 & & 8 \\
\hline
\end{tabular}

In the anticoagulant group all deaths were of men. $\mathrm{A}=\mathrm{s}$ 'atients still on anticoagulant. $\mathrm{B}=$ patients who stopped anticoagulant but continued clofibrate or placebo. 
TABLE VII-Deaths and Non-fatal First Infarcts in Trial

\begin{tabular}{|c|c|c|c|c|c|}
\hline & \multicolumn{2}{|c|}{ Deaths } & & \multicolumn{2}{|c|}{ Infarcts } \\
\hline & Clofibrate & Placebo & & Clofibrate & Placebo \\
\hline \multicolumn{6}{|c|}{ Double-blind Group } \\
\hline Sudden deaths & 13 & 18 & First infarct sur- & & \\
\hline Fatal infarcts & 17 & 11 & $\begin{array}{l}\text { trial } \\
\text { First infarct }\end{array}$ & 14 & \\
\hline Congestive H.F. & 0 & 3 & $\begin{array}{l}\text { dying at subse- } \\
\text { quent event }\end{array}$ & 5 & 4 \\
\hline Total deaths & 30 & 32 & $\begin{array}{l}\text { Total non-fatal } \\
\text { first infarcts }\end{array}$ & 19 & 29 \\
\hline$\%$ Mortality & $11 \cdot 4$ & $11 \cdot 7$ & $\begin{array}{l}\% \text { Non-fatal first } \\
\text { infarcts }\end{array}$ & $7 \cdot 2$ & $10 \cdot 6$ \\
\hline $\begin{array}{l}\text { Rate } 1,200 \\
\text { patient-months }\end{array}$ & $3 \cdot 41$ & $3 \cdot 31$ & $\begin{array}{l}\text { Rate/1,200 } \\
\text { patient-months }\end{array}$ & $2 \cdot 24$ & $3 \cdot 23$ \\
\hline \multicolumn{6}{|c|}{ Anticoagulant Group } \\
\hline Sudden deaths & 2 & 3 & First infarct sur- & & \\
\hline Fatal infarcts & 2 & 3 & trial & 6 & 12 \\
\hline Congestive H.F. & 0 & 0 & $\begin{array}{l}\text { dying at subse- } \\
\text { quent event }\end{array}$ & 0 & 0 \\
\hline Total deaths & 4 & 6 & $\begin{array}{l}\text { Total non-fatal } \\
\text { first infarcts }\end{array}$ & 6 & 12 \\
\hline$\%$ Mortality & $4 \cdot 7$ & $6 \cdot 4$ & $\begin{array}{l}\% \text { Non-fatal } \\
\text { first infarcts }\end{array}$ & $7 \cdot 0$ & $12 \cdot 8$ \\
\hline $\begin{array}{l}\text { Rate } 1,200 \\
\text { patient-months }\end{array}$ & $1 \cdot 34$ & 1.92 & $\begin{array}{l}\text { Rate } / 1,200 \\
\text { patient-months }\end{array}$ & $2 \cdot 07$ & $4 \cdot 11$ \\
\hline \multicolumn{6}{|c|}{ Combined Groups } \\
\hline Sudden deaths & 15 & 21 & $\begin{array}{l}\text { First infarct } \\
\text { surviving to end }\end{array}$ & & \\
\hline Fatal infarcts & 19 & 14 & $\begin{array}{l}\text { of trial } \\
\text { First infarct }\end{array}$ & 20 & 37 \\
\hline Congestive H.F. & 0 & 3 & $\begin{array}{c}\text { dying at subse- } \\
\text { quent event }\end{array}$ & 5 & 4 \\
\hline Total deaths & 34 & 38 & $\begin{array}{l}\text { Total non-fatal } \\
\text { infarcts }\end{array}$ & 25 & 41 \\
\hline$\%$ Mortality & $9 \cdot 7$ & $10 \cdot 4$ & $\begin{array}{l}\% \text { Non-fatal } \\
\text { first infarcts }\end{array}$ & $7 \cdot 1$ & $11 \cdot 2$ \\
\hline $\begin{array}{l}\text { Rate } / 1,200 \\
\text { patient-months }\end{array}$ & $2 \cdot 89$ & $2 \cdot 97$ & $\begin{array}{l}\text { Rate } / 1,200 \\
\text { patient-months }\end{array}$ & $2 \cdot 20$ & $3 \cdot 45$ \\
\hline
\end{tabular}

None of the differences displayed in this table is significant $(P<0.05)$

The rate of non-fatal first infarcts is calculated on the basis of their cumulative patient-months up to the time of those infarcts.

angina, and the death rate per 1,200 patient-months for "all anginas" in the combined series was 1.50 in the clofibrate group compared with 3.97 in the placebo group.

There were significantly more fatal infarcts in men in the "infarct only" group treated with clofibrate $(3.05 / 1,200$ patientmonths) compared with the placebo group $(0.48 / 1,200$ patientmonths) (double-blind group-Table IX). This difference is also evident in Table VIII, where all deaths, less those dying from congestive heart failure, are considered for the subcategory "infarct only"; there were 22 deaths in the clofibrate group and eight in the placebo group in the double-blind section $(P<0.02)$ and 26 and 12 in the combined section $(P<0.03)$ This unfavourable finding is also reflected in the sudden and fatal infarct rates for the combined groups (Table IX); again, it is relevant to point out that the death rate in the placebo group is unexpectedly low $(2 \cdot 14 / 1,200$ patient-months).

\section{NON-FATAL FIRST MYOCARDIAL INFARCT}

In Table $\mathrm{X}$ the number of non-fatal first myocardial infarcts is shown in relation to the initial category of diagnosis for the double-blind, anticoagulant, and combined groups. Table XI shows the same findings and expresses the frequency of non-fatal myocardial infarcts according to rates per 1,200 patient-months. There were no significant differences between the groups, despite an apparent trend in the category "all anginas" in favour of clofibrate $(2 \cdot 13 / 1,200$ patient-months $)$ compared with placebo (3.78/1,200 patient-months). The frequency of non-fatal recurrent myocardial infarction in survivors of the first infarct in the trial was the same in the clofibrate and placebo groups (Reserve Table 9).

\section{FATAL AND NON-FATAL MYOCARDIAL INFARCTS}

Table XII shows the rate per 1,200 patent-months for all myocardial infarcts (fatal and non-fatal combined) according to the category of diagnosis on admission to the trial. There was a significant reduction in the "angina + myocardial infarction" subgroup treated with clofibrate when compared with the placebo group $(P<0.05)$; there were no other significant differences.

\section{TIMING OF EVENTS}

More events occurred during the first six months compared with any subsequent six-month period but clofibrate did not have any more or less notable effect on any category of event during the first six months (Reserve Table 7).

An equivalent reduction in total events in the "all anginas" group occurred during the first and second two-year period. The subgroup in which the difference between the clofibrate and placebo groups was most pronounced was the "angina + myocardial infarct" and there was significant reduction in deaths and all events by the second year of the trial and thereafter. There was no reduction in total events in the "all infarcts" group, but a significant reduction $(P<0.05)$ in the number of non-fatal myocardial infarcts, though not for either category of death, in the "all infarcts" group in the first two years compared with the second two years, yielding an overall significant difference for all groups (11 compared with 26 in the first two years and 14 compared with 15 in the second two years).

\section{OTHER FEATURES OF EVENTS}

No assessment was made of the effect of clofibrate on the incidence and severity of angina. There was no significant difference in events according to age of patients at entry into the trial (Reserve Table 8) or according to the participating hospital where the events were recorded (Reserve Table 9). There was also no significant difference between the groups in the time between entry into the trial and the occurrence of the first non-fatal or fatal myocardial infarct (Reserve Table 10).

Smoking Habits.-In Table XIII the smoking habits at the start of the trial are shown in relation to the subsequent events for the clofibrate-treated and placebo groups. The most striking

TABLE IX-Deaths/1,200 Patient-months

Anticoagulant

\begin{tabular}{|c|c|c|c|}
\hline & & Clofibrate & Placebo \\
\hline $\begin{array}{l}\text { Patients still on anticoagulants } \\
\text { Patients after withdrawal of anticoagulant } \\
\text { All patients } \quad \ldots \quad \ldots \quad \ldots \quad \ldots\end{array}$ & $\begin{array}{ll}\cdots & \cdots \\
\cdots & \cdots\end{array}$ & $\begin{array}{l}2.05 \\
0.66 \\
1.34\end{array}$ & $\begin{array}{l}1.60 \\
2 \cdot 42 \\
1 \cdot 92\end{array}$ \\
\hline
\end{tabular}

\begin{tabular}{|c|c|c|c|c|c|c|c|c|c|c|}
\hline & \multicolumn{5}{|c|}{ Clofibrate } & \multicolumn{5}{|c|}{ Placebo } \\
\hline & \multicolumn{2}{|c|}{ Sudden } & \multicolumn{2}{|c|}{$\begin{array}{c}\text { Fatal } \\
\text { Infarct }\end{array}$} & \multirow[t]{2}{*}{ Total } & \multicolumn{2}{|c|}{ Sudden } & \multicolumn{2}{|c|}{$\begin{array}{c}\text { Fatal } \\
\text { Infarct }\end{array}$} & \multirow[t]{2}{*}{ Total } \\
\hline & M. & F. & $M$ & F. & & M. & F. & M. & F. & \\
\hline \multicolumn{11}{|c|}{ Double-blind } \\
\hline $\begin{array}{l}\text { Angina only } \\
\text { Infarct only } \\
\text { Angina }+ \text { infarct } \\
\text { All anginas } \\
\text { All infarcts }\end{array}$ & $\begin{array}{l}1 \cdot 26 \\
2.54 \\
0.78 \\
1 \cdot 04 \\
2 \cdot 11 \\
\end{array}$ & $\begin{array}{l}= \\
\bar{z}\end{array}$ & $\begin{array}{l}1 \cdot 26 \\
3.05 \\
1.55 \\
1.39 \\
2.68 \\
\end{array}$ & $\begin{array}{l}0.89 \\
\overline{0} \\
-\end{array}$ & $\begin{array}{l}1.84 \\
4.92 \\
1.86 \\
1.85 \\
4 \cdot 11\end{array}$ & $\begin{array}{l}2 \cdot 15 \\
1 \cdot 20 \\
4 \cdot 25 \\
2 \cdot 86 \\
1 \cdot 87\end{array}$ & $\begin{array}{l}1 \cdot 14 \\
5 \cdot 23 \\
2 \cdot 37 \\
1 \cdot 77\end{array}$ & $\begin{array}{l}1 \cdot 29 \\
0.48+ \\
3 \cdot 40 \\
2 \cdot 00 \\
1 \cdot 12\end{array}$ & \begin{tabular}{l|}
- \\
$1 \cdot 34$ \\
$2 \cdot 61$ \\
$0 \cdot 79$ \\
$1 \cdot 77$
\end{tabular} & $\begin{array}{l}2 \cdot 81 \\
2 \cdot 24 \\
7 \cdot 70^{*} \\
4 \cdot 41^{+} \\
3 \cdot 55\end{array}$ \\
\hline Total & 1.91 & - & 2.35 & 0.50 & 3.41 & 1.96 & 1.49 & $1 \cdot 17$ & 1.00 & 3.31 \\
\hline \multicolumn{11}{|c|}{ Combined } \\
\hline $\begin{array}{l}\text { Angina only } \\
\text { Infarct only } \\
\text { Angina + infarct } \\
\text { All anginas } \\
\text { All infarcts }\end{array}$ & $\begin{array}{l}0.94 \\
2.09 \\
0.58 \\
0.78 \\
1.74\end{array}$ & $\begin{array}{l}\text { 二 } \\
=\end{array}$ & \begin{tabular}{|l|}
$0 \cdot 94$ \\
$2 \cdot 44$ \\
$1 \cdot 16$ \\
$1 \cdot 04$ \\
$2 \cdot 14$ \\
\end{tabular} & $\mid \begin{array}{l}0.89 \\
\bar{z} \\
0.68 \\
--\end{array}$ & $\begin{array}{l}1.54 \\
4.04 \\
1.44 \\
1.50 \\
3.40 \\
\end{array}$ & $\begin{array}{l}1.83 \\
1 \cdot 15 \\
3.83 \\
2.56 \\
1.70 \\
\end{array}$ & \begin{tabular}{l|}
0.98 \\
$4 \cdot 22$ \\
$2 \cdot 01$ \\
$1 \cdot 45$ \\
\end{tabular} & \begin{tabular}{|l|}
$1 \cdot 10$ \\
$0 \cdot 66$ \\
$3 \cdot 19$ \\
$1 \cdot 86$ \\
$1 \cdot 17$ \\
\end{tabular} & $\begin{array}{l}-1 \cdot 11 \\
2 \cdot 11 \\
0 \cdot 67 \\
1.45 \\
\end{array}$ & \begin{tabular}{|c|}
$2 \cdot 40$ \\
$2 \cdot 14$ \\
$6 \cdot 86 \pm$ \\
$3 \cdot 97^{\ddagger}$ \\
$3 \cdot 21$ \\
\end{tabular} \\
\hline Total & 1.56 & - & 1.88 & 0.46 & $2 \cdot 89$ & 1.73 & $1 \cdot 25$ & $1 \cdot 15$ & 0.84 & 2.97 \\
\hline
\end{tabular}

A significant difference in the placebo group from the corresponding figure in the clofibrate group is indicated by $* \mathrm{P}<0.05,+\mathrm{P}<0.02, \pm \mathrm{P}<0.01$.
The totals include a small number (see Table VIII) of deaths due to congestive heart failure. 
TABLE X-First Non-fatal Infarcts in Trial

Anticoagulan

\begin{tabular}{|c|c|c|c|c|c|c|c|c|c|c|c|c|c|c|c|c|c|c|c|c|c|c|c|c|}
\hline & \multicolumn{12}{|c|}{ Clofibrate } & \multicolumn{12}{|c|}{ Placebo } \\
\hline & \multirow{2}{*}{\multicolumn{2}{|c|}{$\begin{array}{l}\text { No. in } \\
\text { Group on } \\
\text { Entry }\end{array}$}} & \multicolumn{4}{|c|}{ Definite } & \multicolumn{4}{|c|}{$\begin{array}{c}\text { Definite and } \\
\text { Probable }\end{array}$} & \multirow{2}{*}{\multicolumn{2}{|c|}{ Total }} & \multirow{2}{*}{\multicolumn{2}{|c|}{$\begin{array}{l}\text { No. in } \\
\text { Group on } \\
\text { Entry }\end{array}$}} & \multicolumn{4}{|c|}{ Definite } & \multicolumn{4}{|c|}{$\begin{array}{l}\text { Definite and } \\
\text { Probable }\end{array}$} & \multirow{2}{*}{\multicolumn{2}{|c|}{ Total }} \\
\hline & & & \multicolumn{2}{|c|}{ A } & \multicolumn{2}{|c|}{ B } & \multicolumn{2}{|c|}{ A } & \multicolumn{2}{|c|}{ B } & & & & & \multicolumn{2}{|c|}{ A } & \multicolumn{2}{|c|}{ B } & \multicolumn{2}{|c|}{ A } & \multicolumn{2}{|r|}{ B } & & \\
\hline & M. & $\mathrm{F}$. & M. & $\mathrm{F}$. & M. & F. & M. & F. & M. & $\mathrm{F}$ & A & B & M. & F. & M. & F. & M. & F. & $M$. & F. & M. & F. & A & B \\
\hline $\begin{array}{l}\text { Angina only } \\
\text { Infarct only } \\
\text { Angina - infarct } \\
\text { All anginas } \\
\text { All infarcts }\end{array}$ & $\begin{array}{l}13 \\
56 \\
12 \\
25 \\
68\end{array}$ & $\begin{array}{l}0 \\
4 \\
1 \\
1 \\
5\end{array}$ & $\begin{array}{l}0 \\
1 \\
0 \\
0 \\
1\end{array}$ & $\begin{array}{l}0 \\
0 \\
0 \\
0 \\
0\end{array}$ & $\begin{array}{l}1 \\
3 \\
1 \\
2 \\
4\end{array}$ & $\begin{array}{l}0 \\
0 \\
0 \\
0 \\
0\end{array}$ & $\begin{array}{l}0 \\
1 \\
0 \\
0 \\
1\end{array}$ & $\begin{array}{l}0 \\
0 \\
0 \\
0 \\
0\end{array}$ & $\begin{array}{l}1 \\
3 \\
1 \\
2 \\
4\end{array}$ & $\begin{array}{l}0 \\
0 \\
0 \\
0 \\
0\end{array}$ & $\begin{array}{l}0 \\
1 \\
0 \\
0 \\
1\end{array}$ & $\begin{array}{l}1 \\
3 \\
1 \\
2 \\
4\end{array}$ & $\begin{array}{l}15 \\
56 \\
15 \\
30 \\
71 \\
\end{array}$ & $\begin{array}{l}1 \\
5 \\
2 \\
3 \\
7\end{array}$ & $\begin{array}{l}1 \\
4 \\
0 \\
1 \\
4 \\
\end{array}$ & $\begin{array}{l}0 \\
0 \\
1 \\
1 \\
1\end{array}$ & $\begin{array}{l}1 \\
3 \\
0 \\
1 \\
3 \\
\end{array}$ & $\begin{array}{l}0 \\
0 \\
0 \\
0 \\
0\end{array}$ & $\begin{array}{l}1 \\
4 \\
1 \\
2 \\
5\end{array}$ & $\begin{array}{l}0 \\
0 \\
1 \\
1 \\
1\end{array}$ & $\begin{array}{l}1 \\
3 \\
1 \\
2 \\
4 \\
\end{array}$ & $\begin{array}{l}0 \\
0 \\
0 \\
0 \\
0\end{array}$ & $\begin{array}{l}1 \\
4 \\
2 \\
3 \\
6\end{array}$ & $\begin{array}{l}1 \\
3 \\
1 \\
2 \\
4\end{array}$ \\
\hline Total & 81 & 5 & 1 & 0 & 5 & 0 & 1 & 0 & 5 & 0 & 1 & 5 & 86 & 8 & 5 & 1 & 4 & 0 & 6 & 1 & 5 & 0 & 7 & 5 \\
\hline
\end{tabular}

$\mathrm{A}=$ Patients still on anticoagulant. $\mathrm{B}=$ Patients who had stopped anticoagulant but continued on clofibrate or placebo.

Double-blind

\begin{tabular}{|c|c|c|c|c|c|c|c|c|c|c|c|c|c|c|c|c|}
\hline & & & \multicolumn{7}{|c|}{ Clofibrate } & \multicolumn{7}{|c|}{ Placebo } \\
\hline & & & \multicolumn{2}{|c|}{$\begin{array}{l}\text { No. in Group } \\
\text { on Entry }\end{array}$} & \multicolumn{2}{|c|}{ Definite } & \multicolumn{2}{|c|}{$\begin{array}{l}\text { Definite and } \\
\text { Probable }\end{array}$} & \multirow{2}{*}{ Total } & \multicolumn{2}{|c|}{$\begin{array}{l}\text { No. in Group } \\
\text { on Entry }\end{array}$} & \multicolumn{2}{|c|}{ Definite } & \multicolumn{2}{|c|}{$\begin{array}{l}\text { Definite and } \\
\text { Probable }\end{array}$} & \multirow{2}{*}{ Total } \\
\hline & & & M. & $\mathrm{F}$. & M. & F. & M. & $\mathrm{F}$. & & M. & F. & M. & F. & M. & F. & \\
\hline $\begin{array}{l}\text { Angina only ... } \\
\text { Infarct only } \\
\text { Angina }+ \text { infarct } \\
\text { All anginas .. } \\
\text { All infarcts .. }\end{array}$ & $\begin{array}{l}\cdots \\
\cdots \\
\cdots \\
\cdots\end{array}$ & $\begin{array}{l}\cdots \\
\cdots \\
\cdots \\
\cdots\end{array}$ & $\begin{array}{r}49 \\
124 \\
34 \\
83 \\
158\end{array}$ & $\begin{array}{l}28 \\
19 \\
10 \\
38 \\
29\end{array}$ & $\begin{array}{r}3 \\
8 \\
2 \\
5 \\
10\end{array}$ & $\begin{array}{l}1 \\
2 \\
0 \\
1 \\
2\end{array}$ & $\begin{array}{r}3 \\
8 \\
5 \\
8 \\
13\end{array}$ & $\begin{array}{l}1 \\
2 \\
0 \\
1 \\
2\end{array}$ & $\begin{array}{r}4 \\
10 \\
5 \\
9 \\
15\end{array}$ & $\begin{array}{r}64 \\
119 \\
36 \\
100 \\
155\end{array}$ & $\begin{array}{l}24 \\
20 \\
10 \\
34 \\
30\end{array}$ & $\begin{array}{r}4 \\
12 \\
7 \\
11 \\
19\end{array}$ & $\begin{array}{l}2 \\
0 \\
1 \\
3 \\
1\end{array}$ & $\begin{array}{r}4 \\
13 \\
7 \\
11 \\
20\end{array}$ & $\begin{array}{l}2 \\
4 \\
2 \\
4 \\
3\end{array}$ & $\begin{array}{r}6 \\
11 \\
9 \\
15 \\
23\end{array}$ \\
\hline Total & $\ldots$ & $\cdots$ & 207 & 57 & 13 & 3 & 16 & 3 & 19 & 219 & 54 & 23 & 3 & 24 & 5 & 29 \\
\hline \multicolumn{17}{|c|}{ Combined } \\
\hline & & & \multicolumn{7}{|c|}{ Clofibrate } & \multicolumn{7}{|c|}{ Placebo } \\
\hline & & & \multicolumn{2}{|c|}{$\begin{array}{l}\text { No. in Group } \\
\text { on Entry }\end{array}$} & \multicolumn{2}{|c|}{ Definite } & \multicolumn{2}{|c|}{$\begin{array}{l}\text { Definite and } \\
\text { Probable }\end{array}$} & \multirow{2}{*}{ Total } & \multicolumn{2}{|c|}{$\begin{array}{l}\text { No. in Group } \\
\text { on Entry }\end{array}$} & \multicolumn{2}{|c|}{ Definite } & \multicolumn{2}{|c|}{$\begin{array}{c}\text { Definite and } \\
\text { Probable }\end{array}$} & \multirow{2}{*}{ Total } \\
\hline & & & M. & F. & M. & F. & M. & F. & & M. & F. & M. & F. & M. & F. & \\
\hline $\begin{array}{l}\text { Angina only ... } \\
\text { Infarct only } \\
\text { Angina } \perp \text { infarct } \\
\text { All anginas ... } \\
\text { All infarcts ... }\end{array}$ & $\begin{array}{l}\cdots \\
\cdots \\
\cdots \\
\cdots\end{array}$ & $\begin{array}{l}\cdots \\
\cdots \\
\cdots \\
\cdots\end{array}$ & $\begin{array}{r}62 \\
180 \\
46 \\
108 \\
226\end{array}$ & $\begin{array}{l}28 \\
23 \\
11 \\
39 \\
34\end{array}$ & $\begin{array}{r}4 \\
12 \\
3 \\
7 \\
15\end{array}$ & $\begin{array}{l}1 \\
2 \\
0 \\
1 \\
2\end{array}$ & $\begin{array}{r}4 \\
12 \\
6 \\
10 \\
18\end{array}$ & $\begin{array}{l}1 \\
2 \\
0 \\
1 \\
2\end{array}$ & $\begin{array}{r}5 \\
14 \\
6 \\
11 \\
20\end{array}$ & $\begin{array}{r}79 \\
175 \\
51 \\
130 \\
226 \\
\end{array}$ & $\begin{array}{l}25 \\
25 \\
12 \\
37 \\
37\end{array}$ & $\begin{array}{r}6 \\
19 \\
7 \\
13 \\
26\end{array}$ & $\begin{array}{l}2 \\
0 \\
2 \\
4 \\
2\end{array}$ & $\begin{array}{r}6 \\
20 \\
9 \\
15 \\
29\end{array}$ & $\begin{array}{l}2 \\
1 \\
3 \\
5 \\
4\end{array}$ & $\begin{array}{r}8 \\
21 \\
12 \\
20 \\
33\end{array}$ \\
\hline Total & $\ldots$ & $\ldots$ & 288 & 62 & 19 & 3 & 22 & 3 & 25 & 305 & 62 & 32 & 4 & 35 & 6 & 41 \\
\hline
\end{tabular}

feature of this table is that there were more events of all types among cigarette smokers compared with non-smokers, and this is evident in both subcategories of "all anginas" and "all infarcts." In the "all anginas" group clofibrate reduced all events significantly in cigarette smokers; a similar trend which did not reach significance was evident in non-smokers.

Serum Cholesterol.-In Fig. 1 the serum cholesterol response is shown according to treatment group and sex in relation to

TABLE XI-First Non-fatal Infarcts: Rates/1,200 Patient-months

Anticoagulant

\begin{tabular}{|c|c|c|c|c|c|c|c|c|c|c|}
\hline & & & & & & & \multicolumn{2}{|c|}{ Clofibrate } & \multicolumn{2}{|c|}{ Placebo } \\
\hline \multicolumn{5}{|c|}{$\begin{array}{l}\text { Patients still on anticoagulants } \\
\text { Patients after withdrawal of anticoagulants } \\
\text { All patients }\end{array}$} & $\because$ &.. & & $\begin{array}{l}0 \cdot 69 \\
3 \cdot 46 \\
2 \cdot 07\end{array}$ & & $\begin{array}{l}3.88 \\
4.49 \\
4 \cdot 11\end{array}$ \\
\hline \multicolumn{11}{|l|}{$\ldots$} \\
\hline & \multicolumn{5}{|c|}{ Clofibrate } & \multicolumn{5}{|c|}{ Placebo } \\
\hline & \multicolumn{2}{|c|}{ Definite } & \multicolumn{2}{|c|}{$\begin{array}{c}\text { Definite } \\
\text { and } \\
\text { Probable }\end{array}$} & \multirow[t]{2}{*}{ Total } & \multicolumn{2}{|c|}{ Definite } & \multicolumn{2}{|c|}{$\begin{array}{l}\text { Definite } \\
\text { and } \\
\text { Probable }\end{array}$} & \multirow[t]{2}{*}{ Tota } \\
\hline & M. & $\mathrm{F}$. & M. & F. & & M. & F. & M. & F. & \\
\hline \multicolumn{11}{|c|}{ Double-blind } \\
\hline $\begin{array}{l}\text { Angina only } \\
\text { Infarct only } \\
\text { Angina infarct } \\
\text { All anginas } \\
\text { All infarcts }\end{array}$ & $\begin{array}{l}1.97 \\
2.11 \\
1.63 \\
1.82 \\
1.99\end{array}$ & $\begin{array}{l}0.90 \\
3.93 \\
0.70 \\
2.39\end{array}$ & $\begin{array}{l}1.97 \\
2.11 \\
4.08 \\
2.91 \\
2.59\end{array}$ & $\begin{array}{l}0.90 \\
3.93 \\
0 \cdot 70 \\
2.39\end{array}$ & $\begin{array}{l}1.52 \\
2.32 \\
3.22 \\
2.15 \\
2.56 \\
\end{array}$ & \begin{tabular}{r|r|}
$1 \cdot 83$ \\
$3 \cdot 07$ \\
$7 \cdot 17$ \\
$3 \cdot 47$ \\
$3 \cdot 89$ \\
\end{tabular} & $\begin{array}{l}2.44 \\
2.83 \\
2.56 \\
0.92\end{array}$ & $\begin{array}{l}1 \cdot 83 \\
3.33 \\
7 \cdot 17 \\
3 \cdot 47 \\
4 \cdot 10\end{array}$ & $\begin{array}{l}2.44 \\
1.37 \\
5.66 \\
3.41 \\
2 \cdot 77 \\
\end{array}$ & \begin{tabular}{|l|}
$1 \cdot 99$ \\
$3 \cdot 02$ \\
$6 \cdot 77$ \\
$3 \cdot 46$ \\
3.86 \\
\end{tabular} \\
\hline Total & 1.98 & 1.55 & 2.44 & 1.55 & $2 \cdot 24$ & $3 \cdot 25$ & 1.58 & \begin{tabular}{|l|}
3.39 \\
\end{tabular} & 2.63 & 3.23 \\
\hline \multicolumn{11}{|c|}{ Combined } \\
\hline $\begin{array}{l}\text { Angina only } \\
\text { Infarct only } \\
\text { Angina + infarct } \\
\text { All anginas } \\
\text { All infarcts }\end{array}$ & $\begin{array}{l}1.95 \\
2.16 \\
1.82 \\
1.89 \\
2.08\end{array}$ & $\begin{array}{l}0.90 \\
2.99 \\
0.68 \\
1.95\end{array}$ & $\begin{array}{l}1.95 \\
2.16 \\
3.64 \\
2.70 \\
2.50\end{array}$ & $\left|\begin{array}{l}0.90 \\
2.99 \\
0.68 \\
1.95\end{array}\right|$ & $\begin{array}{l}1.58 \\
2.25 \\
2.99 \\
2.13 \\
2 \cdot 43\end{array}$ & $\begin{array}{r}2.32 \\
3.32 \\
5 \cdot 28 \\
3.33 \\
3.69\end{array}$ & $\begin{array}{l}2 \cdot 09 \\
4 \cdot 76 \\
2.91 \\
1.53\end{array}$ & $\begin{array}{l}2.32 \\
3.50 \\
6.78 \\
3.84 \\
4.12\end{array}$ & $\begin{array}{l}2.09 \\
1.13 \\
7.14 \\
3.63 \\
3.06\end{array}$ & $\begin{array}{l}2 \cdot 26 \\
3 \cdot 18 \\
6.87 \\
3.78 \\
3.95\end{array}$ \\
\hline Total & 2.05 & 1.41 & $2 \cdot 38$ & 1.41 & $2 \cdot 20$ & 3.32 & $\mid 1.77$ & 3.64 & 2.65 & 3.45 \\
\hline
\end{tabular}

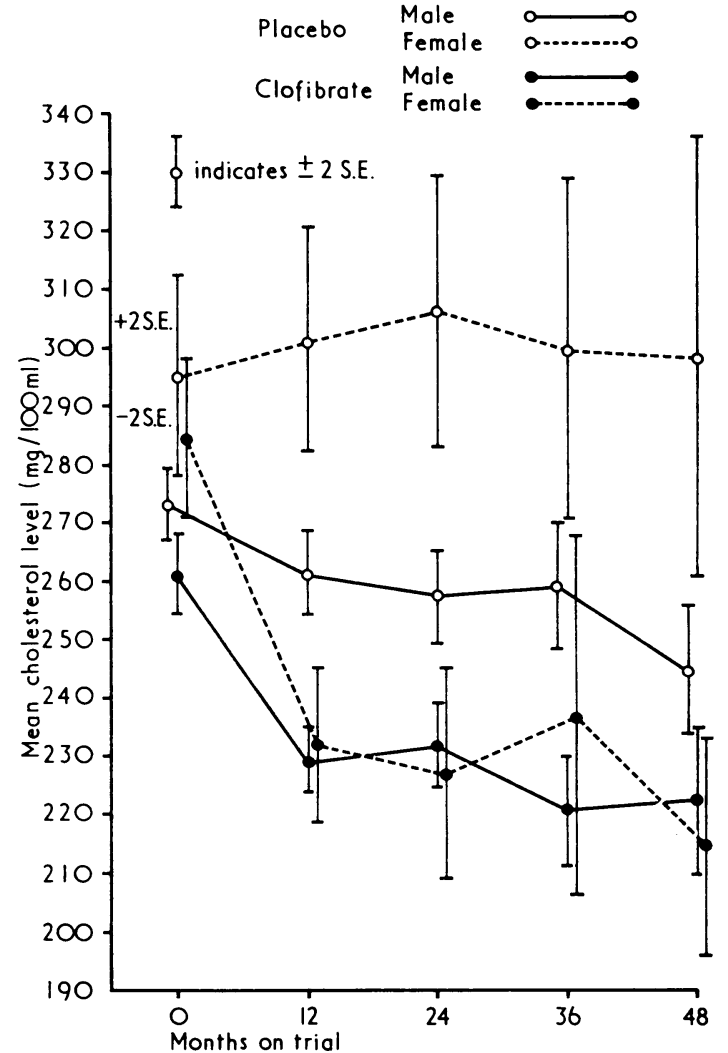

FIG. 1-Mean serum cholesterol levels in clofibrate-treated and placebo groups (double-blind subgroup). 
the duration in the trial for the double-blind group. The difference between the mean of the last two annual measurements for the clofibrate and placebo groups was $35 \mathrm{mg} / 100 \mathrm{ml}$ for men and $70 \mathrm{mg} / 100 \mathrm{ml}$ for women. The mean difference in serum cholesterol levels between the clofibrate-treated and placebo groups during the last two years of the study, considering both sexes in the double-blind group only, was $16 \%$. Fig. 2 illustrates the changes in serum cholesterol in the anticoagulant groups.

In Table XIV the initial serum cholesterol levels are expressed for the combined groups according to clofibrate and placebo treatment in relation to events. The figures are given for all patients who survived more than three months-that is, long enough to have a second serum cholesterol measurement made after entry into the trial. As emphasized earlier, the initial mean serum cholesterol level in the placebo group was significantly higher compared with that for the clofibrate group. Response to treatment was defined in arbitrary units (see Table XIV). The response to treatment with clofibrate is clearly seen (26.1) compared with that of the whole placebo group $(5 \cdot 5)$. Those with events of any category responded less well (a range of $7 \cdot 3-17 \cdot 2)$ than those without incidents $(27 \cdot 2)$.

TABLE XII-Fatal and Non-fatal Infarcts: Rates per 1,200 Patient-months

\begin{tabular}{|c|c|c|c|c|c|}
\hline \multicolumn{6}{|c|}{ Anticoagulant } \\
\hline & & & & Clofibrate & Placebo \\
\hline All patients .. & $\ldots$ & $\ldots$ & $\ldots$ & $2 \cdot 69$ & $4 \cdot 81$ \\
\hline
\end{tabular}

\begin{tabular}{|c|c|c|c|c|c|c|c|}
\hline & & \multicolumn{3}{|c|}{ Clofibrate } & \multicolumn{3}{|c|}{ Placebo } \\
\hline & & M. & F. & Total & M. & F. & Total \\
\hline \multicolumn{8}{|c|}{ Double-blind } \\
\hline $\begin{array}{l}\text { Angina only .. } \\
\text { Infarct only . } \\
\text { Angina + infarct } \\
\text { All anginas ... } \\
\text { All infarcts ... }\end{array}$ & $\begin{array}{l}\ldots \\
\cdots \\
\cdots \\
\cdots\end{array}$ & $\begin{array}{l}3 \cdot 15 \\
5 \cdot 08 \\
5 \cdot 43 \\
4 \cdot 17 \\
5 \cdot 17\end{array}$ & $\begin{array}{l}1.78 \\
3.72 \\
1.38 \\
2.31\end{array}$ & $\begin{array}{l}2 \cdot 58 \\
4 \cdot 92 \\
4 \cdot 33 \\
3 \cdot 24 \\
4 \cdot 76\end{array}$ & $\begin{array}{l}3.01 \\
3.59 \\
9 \cdot 35 \\
5 \cdot 14 \\
4 \cdot 86\end{array}$ & $\begin{array}{l}2 \cdot 27 \\
2 \cdot 68 \\
7 \cdot 84 \\
3 \cdot 96 \\
4 \cdot 43\end{array}$ & $\begin{array}{l}2 \cdot 81 \\
3.46 \\
8.98 \\
4 \cdot 83 \\
4 \cdot 79\end{array}$ \\
\hline Total & $\ldots$ & $4 \cdot 70$ & $2 \cdot 01$ & 4.09 & $4 \cdot 30$ & 3.48 & $4 \cdot 13$ \\
\hline \multicolumn{8}{|c|}{ Combined } \\
\hline $\begin{array}{l}\text { Angina only } \ldots \\
\text { Infarct only } \ldots \\
\text { Angina }+ \text { infarct } \\
\text { All anginas } \ldots \\
\text { All infarcts } \ldots \\
\end{array}$ & $\begin{array}{l}\cdots \\
\cdots \\
\cdots \\
\cdots \\
\cdots\end{array}$ & $\begin{array}{l}2 \cdot 82 \\
4.53 \\
4 \cdot 63 \\
3 \cdot 63 \\
4.55\end{array}$ & $\begin{array}{l}1.78 \\
2.86 \\
1.35 \\
1.90\end{array}$ & $\begin{array}{l}2 \cdot 46 \\
4 \cdot 35 \\
3 \cdot 84 \\
3 \cdot 00 \\
4 \cdot 22 \\
\end{array}$ & $\begin{array}{l}3.29 \\
3.93 \\
8.94 \\
5.34 \\
4.96 \\
\end{array}$ & $\begin{array}{l}1 \cdot 97 \\
2 \cdot 21 \\
8 \cdot 44 \\
4 \cdot 02 \\
4 \cdot 36\end{array}$ & $\begin{array}{l}2 \cdot 93 \\
3 \cdot 71 \\
8 \cdot 82 * \\
5 \cdot 00 \\
4 \cdot 86\end{array}$ \\
\hline Total & $\ldots$ & $4 \cdot 17$ & $1 \cdot 84$ & $3 \cdot 74$ & 4.52 & $3 \cdot 34$ & $4 \cdot 30$ \\
\hline
\end{tabular}
A significant difference in the placebo group from the corresponding figure in the
clofibrate group is indicated by $* \mathrm{P}<0.05$.

TABLE XIII-Events by Smoking Habit on Entry. Combined

\begin{tabular}{|c|c|c|c|c|c|c|c|c|c|}
\hline & \multirow{2}{*}{$\begin{array}{l}\text { No. in } \\
\text { Group } \\
\text { on } \\
\text { Entry }\end{array}$} & \multicolumn{2}{|c|}{$\begin{array}{c}\text { Sudden } \\
\text { Death }\end{array}$} & \multicolumn{2}{|c|}{$\begin{array}{l}\text { Fatal } \\
\text { M.I. }\end{array}$} & \multicolumn{2}{|c|}{$\begin{array}{c}\text { Non-fatal } \\
\text { M.I. }\end{array}$} & \multicolumn{2}{|c|}{$\begin{array}{c}\text { All } \\
\text { Events }\end{array}$} \\
\hline & & No. & $\%$ & No. & $\%$ & No. & $\%$ & No. & $\%$ \\
\hline \multicolumn{10}{|c|}{ All Anginas } \\
\hline Clofibrate: & & & & & & & & & \\
\hline $\begin{array}{l}\text { Non-smokers } \\
\text { All smokers }\end{array}$ & $\begin{array}{l}62 \\
97\end{array}$ & $\begin{array}{l}0 \\
3\end{array}$ & $\overline{3 \cdot 1}$ & $\begin{array}{l}1 \\
4\end{array}$ & $\begin{array}{l}1 \cdot 6 \\
4 \cdot 1\end{array}$ & $\begin{array}{l}4 \\
7\end{array}$ & $\begin{array}{l}6 \cdot 5 \\
7 \cdot 2\end{array}$ & $\begin{array}{r}5 \\
14\end{array}$ & $\begin{array}{r}8 \cdot 1 \\
14.4 \mathrm{~A}\end{array}$ \\
\hline Placebo: & & & & & & & & & \\
\hline $\begin{array}{l}\text { Non-smokers } \\
\text { All smokers }\end{array}$ & $\begin{array}{l}80 \\
97\end{array}$ & $\begin{array}{l}5 \\
9\end{array}$ & $\begin{array}{l}6 \cdot 3 \\
9 \cdot 3\end{array}$ & $\begin{array}{l}1 \\
8\end{array}$ & $\begin{array}{l}1 \cdot 3 \\
8 \cdot 3\end{array}$ & $\begin{array}{r}6 \\
14\end{array}$ & $\begin{array}{r}7 \cdot 5 \\
14 \cdot 4\end{array}$ & $\begin{array}{l}12 \\
31\end{array}$ & $\begin{array}{l}15 \cdot 0 \mathrm{~B} \\
32 \cdot 0 \mathrm{C}\end{array}$ \\
\hline \multicolumn{10}{|c|}{ All Infarcts } \\
\hline Clofibrate: & & & & & & & & & \\
\hline Non-smokers & 109 & 3 & $2 \cdot 8$ & 7 & $6 \cdot 4$ & 4 & $3 \cdot 7$ & 14 & $12 \cdot 8$ \\
\hline $\begin{array}{l}\text { All smokers } \\
\text { Placebo: }\end{array}$ & 167 & 10 & $6 \cdot 0$ & 9 & $5 \cdot 4$ & 16 & $9 \cdot 6$ & 35 & $21 \cdot 0$ \\
\hline $\begin{array}{l}\text { Non-smokers } \\
\text { All smokers }\end{array}$ & $\begin{array}{l}117 \\
151\end{array}$ & $\begin{array}{l}6 \\
9\end{array}$ & $\begin{array}{l}5 \cdot 1 \\
6 \cdot 0\end{array}$ & $\begin{array}{l}2 \\
9\end{array}$ & $\begin{array}{l}1 \cdot 7 \\
6 \cdot 0\end{array}$ & $\begin{array}{l}10 \\
23\end{array}$ & $\begin{array}{r}8 \cdot 6 \\
15 \cdot 2\end{array}$ & $\begin{array}{l}20^{*} \\
42^{*}\end{array}$ & $\begin{array}{l}17 \cdot 1 \\
27 \cdot 8\end{array}$ \\
\hline \multicolumn{10}{|c|}{ All patients } \\
\hline Clofibrate: & & & & & & & & & \\
\hline $\begin{array}{l}\text { Non-smokers } \\
\text { All smokers }\end{array}$ & $\begin{array}{l}142 \\
234\end{array}$ & $\begin{array}{r}3 \\
12\end{array}$ & $\begin{array}{l}2 \cdot 1 \\
5 \cdot 1\end{array}$ & $\begin{array}{r}7 \\
12\end{array}$ & $\begin{array}{l}4 \cdot 9 \\
5 \cdot 1\end{array}$ & $\begin{array}{r}5 \\
20\end{array}$ & $\begin{array}{l}3.5 \\
8.6\end{array}$ & $\begin{array}{l}15 \\
44\end{array}$ & $\begin{array}{l}10 \cdot 6 \\
18 \cdot 8\end{array}$ \\
\hline Placebo: & & & & & & & & & \\
\hline Non-smokers & 169 & 8 & $4 \cdot 7$ & 3 & $1 \cdot 8$ & 12 & $7 \cdot 1$ & $25^{*}$ & $14 \cdot 8$ \\
\hline & & 13 & 6.0 & 11 & & 29 & & & $25 \cdot 1$ \\
\hline
\end{tabular}

*Includes some deaths from congestive heart failure.

*Includes some deaths from congesti
A $v$. C P $<0.01$. B $v$. C $\mathrm{P}<0.02$.

Some patients claimed more than one smoking habit on entry. Numbers in group on entry therefore exceed numbers actually in trial.

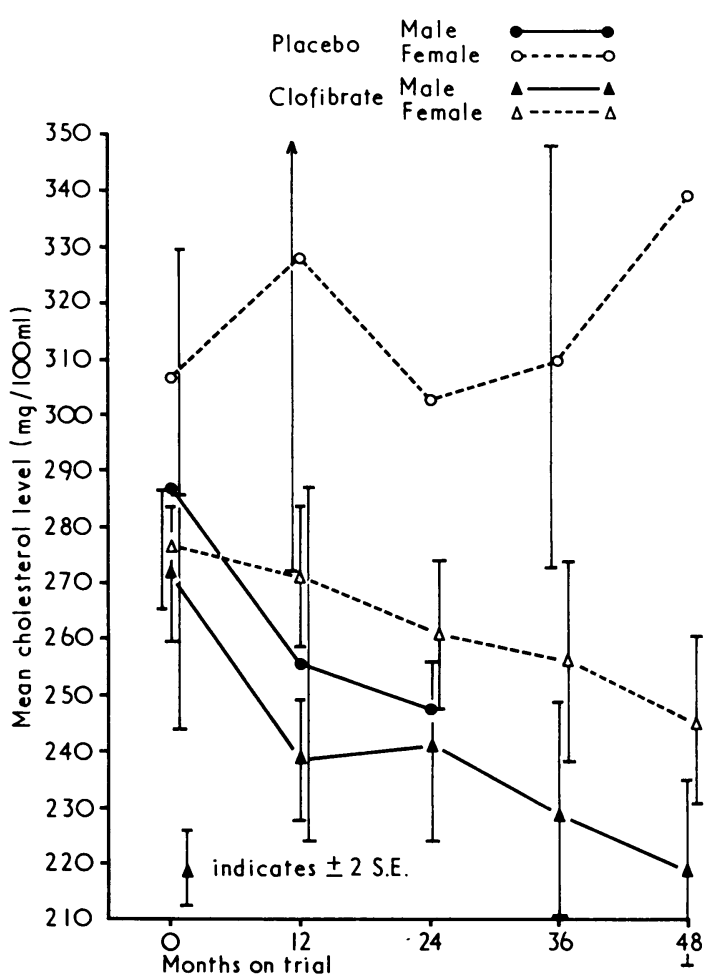

FIG. 2-Mean serum cholesterol levels in clofibrate-treated and placebo groups (anticoagulant subgroup).

TABLE XIV-Incidents Related to History, Initial Cholesterol, and Cholesterol Response (Males Only). Combined

\begin{tabular}{|c|c|c|c|c|c|}
\hline & $\begin{array}{l}\text { Whole } \\
\text { Group }\end{array}$ & $\begin{array}{l}\text { Sudden } \\
\text { Deaths }\end{array}$ & $\begin{array}{c}\text { Fatal } \\
\text { Infarcts }\end{array}$ & $\begin{array}{l}\text { Non-fatal } \\
\text { Infarcts }\end{array}$ & $\begin{array}{c}\text { No } \\
\text { Incidents }\end{array}$ \\
\hline $\begin{array}{l}\text { Clofibrate: } \\
\text { No. of patients } \\
\text { Initial cholesterol }\end{array}$ & & 11 & 12 & 21 & 214 \\
\hline $\begin{array}{cc}(\mathrm{mg} / 100 \mathrm{ml}) & \ldots \\
\text { Response } & \ldots\end{array}$ & $\begin{array}{r}259 \cdot 4 \\
26 \cdot 1\end{array}$ & $\begin{array}{r}253.0 \\
16.5\end{array}$ & $\begin{array}{r}229 \cdot 7 \\
7 \cdot 3\end{array}$ & $\begin{array}{r}258 \cdot 9 \\
17 \cdot 2\end{array}$ & $\begin{array}{r}261 \cdot 1 \\
27 \cdot 2\end{array}$ \\
\hline $\begin{array}{l}\text { No. of patients } \\
\text { Initial cholesterol }\end{array}$ & 281 & 17 & 8 & 32 & 226 \\
\hline $\begin{array}{cc}(\mathrm{mg} / 100 \mathrm{ml}) & \ldots \\
\text { Response } & \ldots\end{array}$ & $\begin{array}{r}271 \cdot 6 \\
5 \cdot 5\end{array}$ & $\begin{array}{r}275 \cdot 8 \\
-5 \cdot 1\end{array}$ & $\begin{array}{r}253 \cdot 8 \\
-4 \cdot 3\end{array}$ & $\begin{array}{r}279 \cdot 6 \\
0.5\end{array}$ & $\begin{array}{r}271 \cdot 0 \\
-7 \cdot 1\end{array}$ \\
\hline
\end{tabular}

Response in units $=$ (Pretreatment cholesterol level - means of all subsequent evels) $\times 100 \div$ (pretreatment level -150 )

Some patients did not have the minimum of three cholesterol levels needed to calculate their response. The numbers of patients in the groups above are consequently smaller than the numbers shown in other tables.

In Table XV the relationship between events occurring during the trial and initial serum cholesterol levels is shown. With an arbitrary division between high and low serum cholesterol levels of $260 \mathrm{mg} / 100 \mathrm{ml}$ or less and more than $260 \mathrm{mg} / 100 \mathrm{ml}$ there was no relationship with subsequent events in the "all anginas" group but a trend is evident in patients categorized as "all myocardial infarcts," suggesting that those with initially high serum cholesterol levels have fewer events when treated with clofibrate (5.73/1,200 manmonths) than when given placebo (7.04/1,200 man-months).

Side Effects.-There was no difference in the incidence or nature of side effects assessed at three months after entry into

TABLE XV-Relationship Between Events During Trial and Initial Cholesterol Levels $(\mathrm{mg} / 100 \mathrm{ml}$ ) in Male Patients

\begin{tabular}{|c|c|c|c|c|c|c|c|c|}
\hline \multirow[b]{3}{*}{ Cholesterol group: } & \multicolumn{4}{|c|}{ All Infarcts } & \multicolumn{4}{|c|}{ All Anginas } \\
\hline & \multicolumn{2}{|c|}{ Clofibrate } & \multicolumn{2}{|c|}{ Placebo } & \multicolumn{2}{|c|}{ Clofibrate } & \multicolumn{2}{|c|}{ Placebo } \\
\hline & $\leqslant 260$ & $\begin{array}{l}>260 \\
\text { High }\end{array}$ & $\begin{array}{r}\leqslant 260 \\
\text { Low }\end{array}$ & $\begin{array}{l}>260 \\
\text { High }\end{array}$ & $\begin{array}{r}\leqslant 260 \\
\text { Low }\end{array}$ & $\begin{array}{l}>260 \\
\text { High }\end{array}$ & $\begin{array}{l}\leqslant 260 \\
\text { Low }\end{array}$ & $\begin{array}{l}>260 \\
\text { High }\end{array}$ \\
\hline 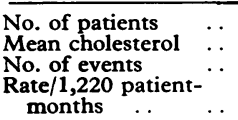 & $\begin{array}{r}125 \\
228 \\
30 \\
8.04\end{array}$ & $\begin{array}{c}99 \\
304 \\
17 \\
5 \cdot 73\end{array}$ & $\begin{array}{r}101 \\
232 \\
23 \\
7 \cdot 3\end{array}$ & $\begin{array}{c}125 \\
308 \\
27 \\
7.04\end{array}$ & $\begin{array}{r}61 \\
221 \\
10 \\
4.97\end{array}$ & $\begin{array}{r}47 \\
307 \\
8 \\
5.58\end{array}$ & $\begin{array}{r}61 \\
223 \\
17 \\
8 \cdot 89\end{array}$ & $\begin{array}{r}68 \\
310 \\
16 \\
8 \cdot 34\end{array}$ \\
\hline
\end{tabular}


the trial and at the final visit in the clofibrate and placebo groups (Reserve Table 11). Muscular pain was not reported in excess in the clofibrate group (Langer and Levy, 1968; Smith et al., 1970).

Deaths from Non-coronary Causes.-These were equally distributed between the clofibrate and placebo groups and included carcinomas (8), cerebrovascular accidents (5), trauma (2), bronchopneumonia (1), and two reported as "non-coronary deaths" (Reserve Table 12).

Weight.-There was no significant change in weight in the clofibrate or placebo groups in either sex (Reserve Fig. $1^{+}$).

Blood Pressure.-There was no significant change in systolic or diastolic blood pressure in the clofibrate or placebo groups in either sex (Reserve Fig. 2).

\section{Discussion}

The results are presented of a multicentre trial of the effects of clofibrate on the secondary prevention of ischaemic heart disease. This trial was conducted on a randomized basis and, with the exception of patients on anticoagulants, double-blind design. In spite of randomizing cases, certain biological differences were not standardized, and it should be noted that men in the clofibrate-treated group had lower blood pressure and lower serum cholesterol levels on entry into the trial compared with those in the placebo group.

The most striking finding is the difference in the apparent effect of clofibrate in patients with angina compared with those with myocardial infarction without associated angina. In those categorized on entry as having "angina + myocardial infarction" the death rate per 1,200 patient-months (Table IX) was significantly reduced in the clofibrate-treated group. A similar but statistically non-significant trend was evident in those categorized on entry as "angina only." When these two categories are added ("all anginas") significant reduction in the rate per 1,200 patient-months is again evident in the clofibrate group. This represents a reduction by $62^{\prime \prime}{ }^{\prime}$ in death rate when compared with the placebo group. This overall reduction of deaths in the subgroups categorized as having angina was reflected in the rates both of sudden death and of fatal myocardial infarcts (as defined).

Clofibrate had no such overall effect on mortality rate in those categorized on entry as "myocardial infarct only" or in the category "all infarcts" (this category comprises the subgroups "infarct only" and "angina + myocardial infarct"). Indeed, there was a higher mortality in the "infarct only" subcategory in the ciofibrate-treated group both for sudden deaths and for fatal myocardial infarcts; this reached statistical significance in the double-blind section so far as fatal myocardial infarcts were concerned (see later comments). This lower annual mortality rate in the "infarct only" subcategory treated with placebo compared with the corresponding clofibrate subcategory $\left(2 \cdot 14^{\circ}{ }_{0}^{\circ}\right.$ compared with $\left.4 \cdot 04^{\circ}{ }_{0}\right)$ was presumably a chance finding.

The expected annual death rate in patients surviving more than one month after first myocardial infarction is reported to vary from 4 to $9^{\circ}$ ( (Honey and Truelove, 1957; Juergens et al., 1960; Pell and D'Alonzo, 1963; Weinblatt et al., 1971), while the annual rate in this study was only $2 \cdot 14^{\prime}$ " for the "infarct only" group and $2.97^{\circ}$, for all groups treated with placebo. The explanation of these low rates is not clear.

While there was no significant reduction in the rate per 1,200 patient-months of first recurrent non-fatal myocardial infarct in patients treated with clofibrate, there was a favourable trend in all subcategories (Tables $\mathrm{X}$ and $\mathrm{XI}$ ) so that the overall rate per 1,200 patient-months in the clofibrate-treated group was 2.20 compared with 3.45 in the placebo group. This is an overall reduction by $36^{\circ} \%$ in the clofibrate group compared with the placebo group.

$\lceil$ Reserves figures available on request.
As regards "all events," clofibrate reduced the rate by $53^{\circ}$ o in the "all anginas" category, which is statistically significant, by $16^{\prime \prime}{ }^{\circ}$ in the "all infarcts" category, and by $21^{\circ}{ }_{0}$ in all categories.

The results of this trial show once again that more coronary events occur in cigarette smokers compared with non-smokers.

When this trial was initiated in 1964 serum lipoprotein analysis and serum triglyceride estimations were not generally available and the only serum lipid which was estimated at regular intervals was serum cholesterol. The chief points to emphasize with regard to serum cholesterol are that (1) there was on entry into the trial a significantly lower initial serum cholesterol in men in the clofibrate-treated group, (2) the response of serum cholesterol to treatment with clofibrate was less in patients with incidents compared with those who did not experience incidents during the trial (Table XIV), (3) the reduction in events in the "all anginas" subcategory was independent of the initial serum cholesterol levels, while reduction in the event rate per 1,200 patient-months was evident only in the "all infarcts" subcategory in patients with an initial serum cholesterol level of more than $260 \mathrm{mg} 100 \mathrm{ml}$ (Table XV).

A further point of importance is that the entry period of patients with myocardial infarction was between 8 and 16 weeks after their first myocardial infarct, and it is possible that in some of these patients the levels of serum cholesterol were still affected by the temporary lowering effect of the recent infarct. Raised scrum cholesterol levels have previously been reported to be of greater prognostic significance in patients with angina in contrast to those with infarction (see Introduction to this paper). It may be relevant, therefore, that clofibrate had a more beneficial effect in patients with angina compared with those with myocardial infarction. The increased mortality rate in the subcategory "infarct only" treated with clofibrate (Table IX) should be considered in conjunction with the initial level of serum cholesterol. There were more males in the "all infarcts" subcategory with a serum cholesterol of $260 \mathrm{mg} / 100 \mathrm{ml}$ or less (125 patients) compared with those with an initial serum cholesterol of more than $260 \mathrm{mg} / 100 \mathrm{ml}$ (99 patients). Since there was no reduction in the event rate per 1,200 patientmonths in those with initially low serum cholesterol levels in the "all infarcts" subcategory, the adverse finding in the "infarct only" subcategory treated with clofibrate may partly be due to weighting of this group with patients with an initially low serum cholesterol level.

Numerous analyses have been made of the relationship of events to initial serum cholesterol levels and to the degree of cholesterol response, and it must be emphasized that the adoption of $260 \mathrm{mg} / 100 \mathrm{ml}$ as a cutting point is arbitrary and open to criticism in that undue reliance is inevitably being placed on the accuracy and significance of the initial serum cholesterol level and that the adoption of a slightly different cutting-off point might produce a different result. Therefore, too much should not be read into these data, but the figures justify a conclusion that clofibrate is not effective in reducing events in patients with myocardial infarction with initially normal serum cholesterol levels.

It would be unwise to assume that the beneficial effects of clofibrate reported in this trial are due to its action on cholesterol metabolism, though changes in plasma cholesterol levels do not reflect in any consistent way changes which occur as a result of clofibrate administration in the slowly miscible tissue pool of cholesterol (Ahrens, 1971). Clofibrate has a more profound effect in reducing raised plasma triglyceride levels (Oliver, 1962, 1963) and also reduces plasma free fatty acids; these actions should not be overlooked. But, in addition, clofibrate decreases fibrinogen levels, increases fibrinolysis (Srivastava et al., 1963), and reduces abnormal platelet stickiness (Gilbert and Mustard, 1963). The beneficial results may, therefore, be unrelated to the plasma-lipid-lowering effect of the drug.

We wish to acknowledge the help and advice in the assembly and analysis of the data given by Dr. C. C. Downie, Dr. R. T. 
Rouse, and Mr. J. M. Thorp, of I.C.I. Pharmaceuticals Limited. We would like to thank Dr. W. Brass, of the London School of Hygiene, for his statistical advice in the initial stages of the trial. This trial was partly financed by a grant from the Scottish Home and Health Department through the Advisory Committee on Medical Research.

Reserve Tables and Reserve Figures and working protocols can be obtained on request. Reprint requests to $\mathrm{Dr}$. M. F. Oliver, Department of Cardiology, Royal Infirmary, Edinburgh EH3 9YW.

\section{References}

Ahrens, E. H. (1971). Proceedings of the IV International Symposium on Drugs Affecting Lipid Metabolism. In press.

Frank, C. W., Weinblatt, E., and Shapiro, S. (1970). Atherosclerosis, ed. R. J. Jones. Berlin-New York, Springer-Verlag.

Gilbert, J. B., and Mustard, J. F. (1963). Journal of Atherosclerosis Research, $3,623$.

Green, K. G., Inman, W. H. W., and Thorp, J. M. (1963). Fournal of Atherosclerosis Research, 3, 593 .

Hellman, L., et al. (1963). Journal of Atherosclerosis Research, 3, 454.

\title{
Secondary Prevention Trials using Clofibrate: A Joint Commentary on the Newcastle and Scottish Trials
}

\author{
H. A. DEWAR, M. F. OLIVER
}

British Medical fournal, 1971, 4, 784-786

\section{Introduction}

The design, conduct, and results of two trials in which an attempt was made to reduce the incidence of infarct and death in patients with ischaemic heart disease are reported on pages 767 and 775 of this issue. This joint commentary is intended to emphasize the salient points of difference and concurrence between the trials established in Newcastle and in Scotland.

\section{Differences in Design}

The main points of difference in design are listed in Table I. In the Scottish trial patients with angina were admitted only if the duration of angina was between 3 and 24 months. In the Newcastle trial no such limits were set. In the Scottish trial patients with myocardial infarction were admitted between 8 and 16 weeks after their first infarct. In the Newcastle trial patients were admitted at any time from six weeks after their last myocardial infarct and no limit was set on the number of previous infarcts. The inclusion in the Scottish trial of patients recovering from recent myocardial infarction might favour a worse short-term prognosis. In the Newcastle trial there were many patients with more than one myocardial infarction and their long-term prognosis is likely to have been worse.

\section{Differences in Conduct}

The main points of difference in conduct are listed in Table II. In the Newcastle trial sudden death was defined as death

Royal Victoria Infirmary, Newcastle upon Tyne NE1 4LP H. A. DEWAR, M.D., F.R.C.P., Consultant Physician and Cardiologist

\section{Royal Infirmary, Edinburgh EH3 9YW}

M. F. OLIVER, M.D., F.R.C.P., Consultant Physician, Department of Cardiology; and Reader in Medicine, University of Edinburgh
Honey, G. E., and Truelove, S. C. (1957). Lancet, 1, 1209.

Juergens, J. L., Edwards, J. E., Achor, R. W. P., and Burchell, H. B. (1960). Archives of Internal Medicine, 105, 444

Kagan, A., Dawber, T. R., Kannel, W. B., and Revotskie, N. (1962). Federation Proceedings, Suppl. 11, p. 52

Langer, T., and Levy, R. I. (1968). New England fournal of Medicine, $279,856$.

Little, J. A., Shanoff, H. M., Row, R. D., Csima, A., and Yano, R. (1965). Circulation, 31, 854

Oliver, M. F. (1962). Lancet, 1, 1321.

Oliver, M. F. (1963). Fournal of Atherosclerosis Research, 3, 679.

Paterson, J. C., Armstrong, R., and Armstrong, E. C. (1963). Circulation, $27,229$.

Pell, S., and D'Alonzo, C. A. (1963). Fournal of the American Medical Association, 185, 831

Smith, A. F., Macfie, W. G., and Oliver, M. F. (1970). British Medical fournal, $2,86$.

Srivastava, S. C., Smith, M. J., and Dewar, H. A. (1963). Fournal of Atherosclerosis Research, 3, 640.

Stamler, J. (1964). Connecticut Medicine, 28, 675.

Truett, J., Cronfield, J., and Kannel, W. (1967). Fournal of Chronic Diseases, 20, 511. Public Health and the Nation's Health, 61, 831.

Westlund, K., and Nicolaysen, R. (1966). Scandinavian Fournal of Clinical and Laboratory Investigation, 18, Suppl. 87.

World Health Organization (1959). Technical Report Series, No. 168.
Weinblatt, E., Shapiro, S., and Frank, C. W. (1971). American fournal of

that was immediate or within a few minutes of symptoms. In the Scottish trial the sudden death category included deaths up to one hour.

TABLE I-Differences in Design between the Newcastle and Scottish Trials Newcastle Scottish

\begin{tabular}{l|l} 
(a) Clinical diagnosis only. Abnormal (a) Diagnosis confirmed by abnormal & (b)
\end{tabular} E.C.G. not insisted on

(b) Duration of more than 3 months but less than 2 years

\section{Previous myocardial infarcts}

(a) No limit on numbers

No formal criteria of diagnosis required

(c) Entry permitted after minimum period of 6 weeks

(d) Average interval between last myocardial infarct and entry into
trial was 1!: years (2-99 months)

(a) Only one allowed

b) W.H.O. criteria of diagnosis and E.C.C.C.s evaluated by one

(c) Entry betwe

8 and 16 weeks

(d) Average interval between myocardial infarct and entry into
trial was 3 months (2-4 months) Electrocardiograms

Interpreted both on entry and on $\mid$ Interpreted on entry, at the time of \begin{tabular}{l|l} 
conclusion by participating physicians & $\begin{array}{l}\text { an event, and on conclusion by one } \\
\text { observer according to WH.O. }\end{array}$ \\
on own criteria
\end{tabular} on own criteri criteria

Anticoagulants

\begin{tabular}{|c|c|}
\hline $\begin{array}{l}\text { Discouraged. Results analysed with } \\
\text { and without this small group }\end{array}$ & Special group formed \\
\hline \multicolumn{2}{|c|}{ Age } \\
\hline $\begin{array}{l}\text { No lower limit } \\
\text { Upper limit } 65 \text { years }\end{array}$ & $\begin{array}{l}\text { Lower limit } 40 \text { years } \\
\text { Upper limit } 69 \text { years }\end{array}$ \\
\hline \multicolumn{2}{|c|}{ Blood Pressure } \\
\hline $\begin{array}{l}\text { Patients with B.P. } 200 / 100 \mathrm{~mm} \mathrm{Hg} \text { or } \\
\text { on treatment for hypertension excluded }\end{array}$ & $\begin{array}{l}\text { Only malignant hypertension } \\
\text { excluded }\end{array}$ \\
\hline \multicolumn{2}{|c|}{ Cholesterol } \\
\hline $\begin{array}{l}\text { Patients with levels of } 400 \mathrm{mg} / 100 \mathrm{ml} \\
\text { and/or xanthomata excluded }\end{array}$ & $\begin{array}{l}\text { No limits imposed (few exceeded } \\
400 \mathrm{mg} 100 \mathrm{ml} \text { ) }\end{array}$ \\
\hline
\end{tabular}

Cigarettes graded $1-10,11-20$, and $\mid$ Cigarettes graded $1-15$ and $>15 /$ day
$>20 /$ day $>20$ day

Clofibrate

Men received 1.6 or $2 \mathrm{~g}$ daily according to weight
received $1.6 \mathrm{~g}$ daily 